\title{
The Rabaul Volcano Observatory Real-Time GPS Upgrade
}

USGS Open-File Report 2005-1232

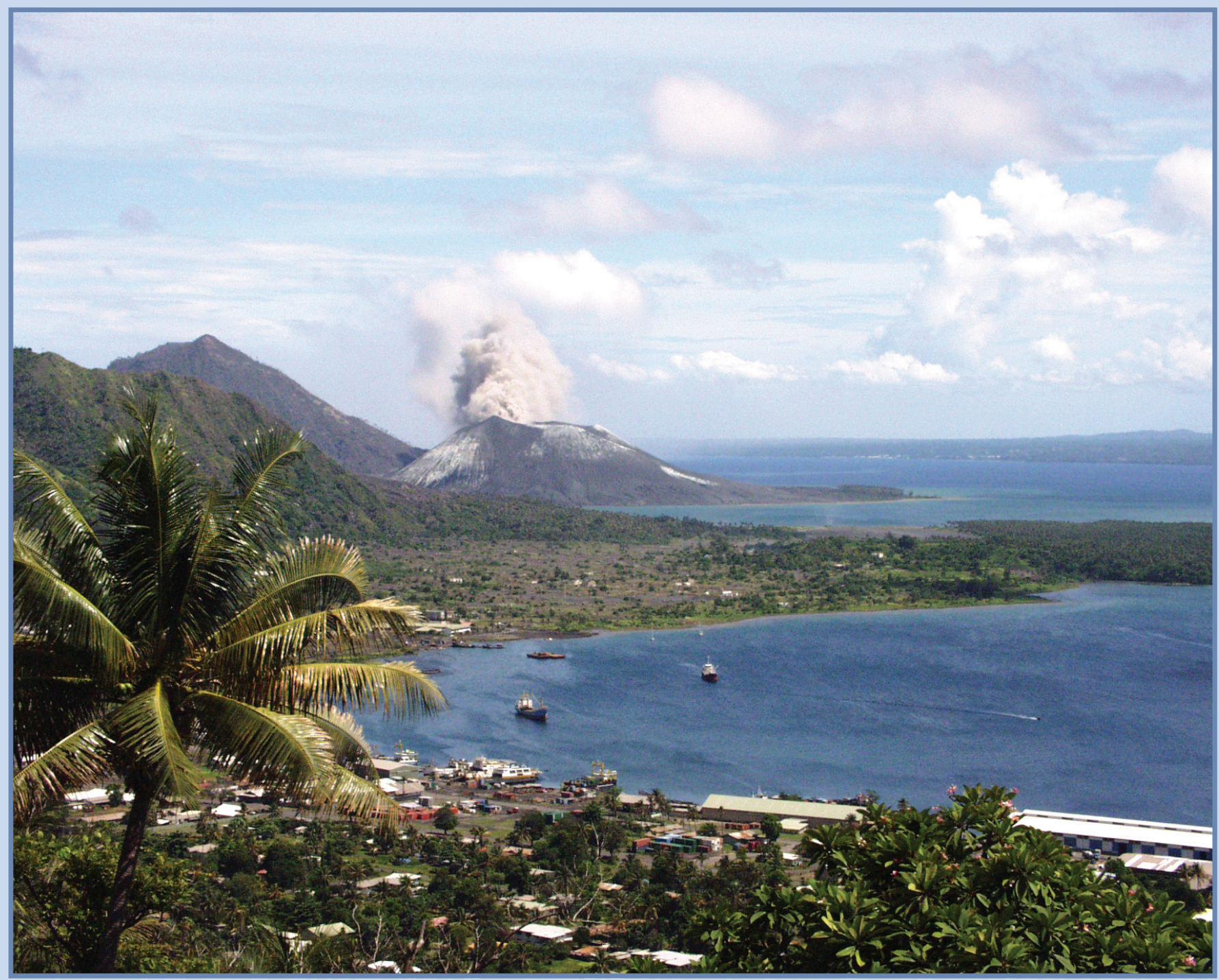




\section{Front Cover:}

Looking across Simpson Bay at Tavurvur, October 1999. Photograph by Elliot Endo (U.S. Geological Survey). 


\title{
The Rabaul Volcano Observatory Real-Time GPS Upgrade
}

\author{
By Elliot Endo
}

Open-File Report 2005-1232 


\section{U.S. Department of the Interior \\ Gale A. Norton, Secretary}

\section{U.S. Geological Survey \\ Charles G. Groat, Director}

U.S. Geological Survey, Vancouver, Washington: 2005

For sale by U.S. Geological Survey, Information Services

Box 25286, Denver Federal Center

Denver, CO 80225

For more information about the USGS and its products:

Telephone: 1 -888-ASK-USGS

World Wide Web: http://www.usgs.gov/

http:www.vulcan.wr.usgs.gov/

Any use of trade, product, or firm names in this publication is for descriptive purposes only and does not imply endorsement by the U.S. Government.

Although this report is in the public domain, permission must be secured from the individual copyright owners to reproduce any copyrighted materials contained within this report. 


\section{CONTENTS}

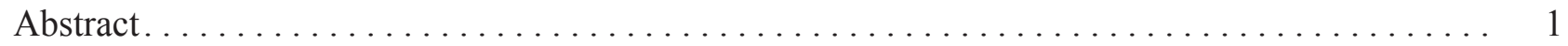

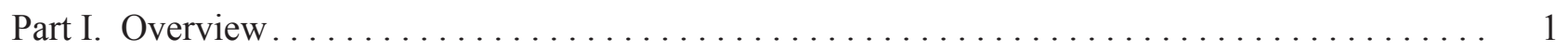

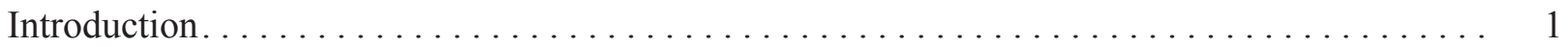

Location and Brief Description of Rabaul ............................ 2

The 1996 GPS Network . . . . . . . . . . . . . . . . . . . . . . . . . . . . . . 2

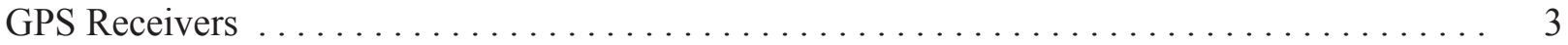

Components of the Real-Time GPS Upgrade $\ldots \ldots \ldots \ldots \ldots \ldots \ldots \ldots \ldots \ldots \ldots \ldots, 4$

Computer .............................................. 4

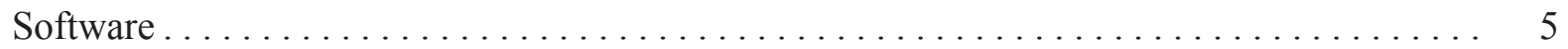

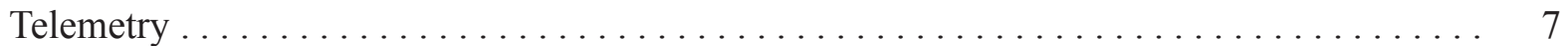

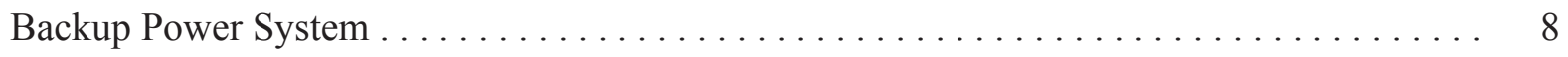

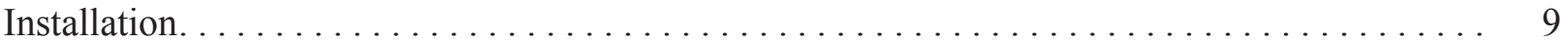

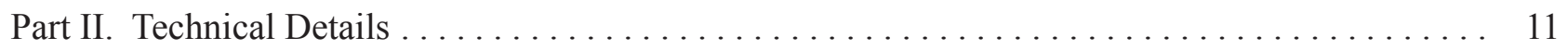

NT Workstation Configuration ................................... 11

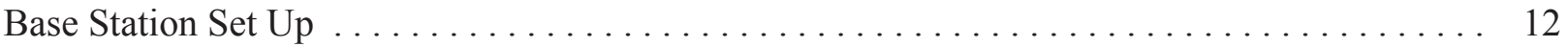

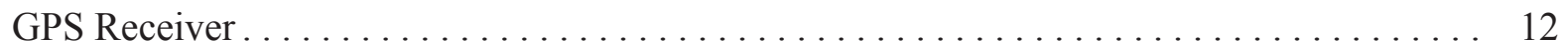

Radio Modems ....................................... 12

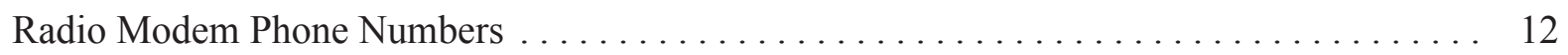

Radio Modem Antennas. . . . . . . . . . . . . . . . . . . . . . . . . . . . 12

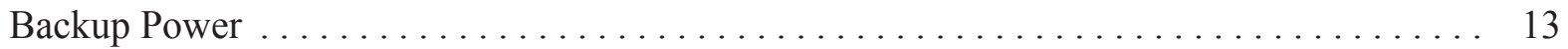

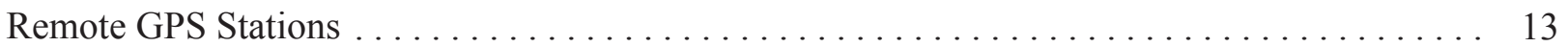

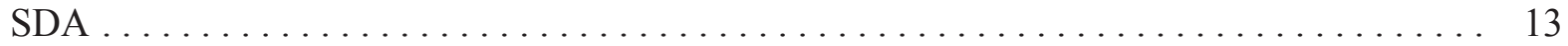

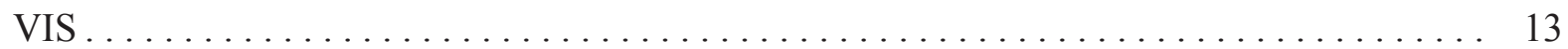

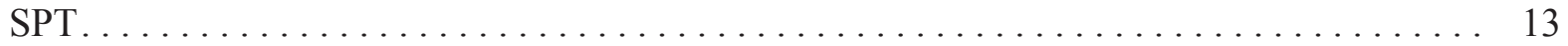

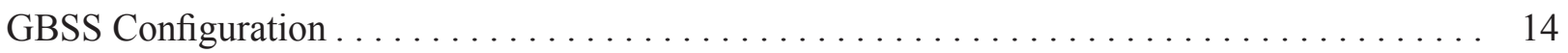

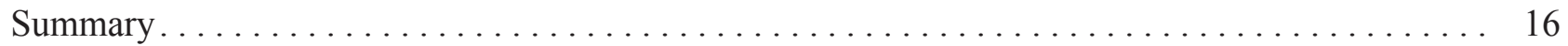

Acknowledgments........................................... 16

References Cited ................................................ 16

Appendixes

A. Short-Baseline Test Results of 3d_Tracker ............................ 19

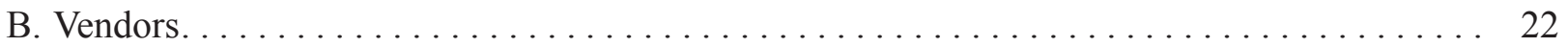

C. Manuals $\ldots \ldots \ldots \ldots \ldots \ldots \ldots \ldots \ldots \ldots \ldots \ldots \ldots \ldots \ldots \ldots \ldots \ldots \ldots \ldots \ldots \ldots \ldots \ldots \ldots \ldots, 22$ 


\section{Figures}

1. Map of the Rabaul caldera area location of GPS and seismic stations $\ldots \ldots \ldots \ldots \ldots 2$

2. Photograph of the antenna for the RVO GPS base station located outside

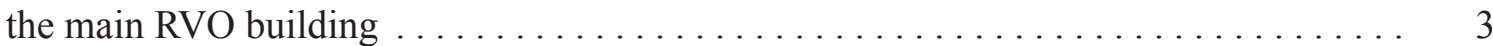

3. Photograph of the SDA GPS station on Matupit Island showing GPS and seismic electronics located at the base of church steeple . . . . . . . . . . . . . .

4. Photograph showing the VUL/VIS vault for GPS receiver tiltmeter and seismic

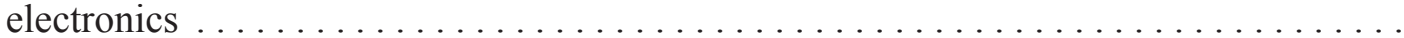

5. Photograph showing SPT vault and GPS antenna $\ldots \ldots \ldots \ldots \ldots \ldots \ldots \ldots \ldots \ldots \ldots \ldots \ldots$

$6 A$. Photograph showing panels and radio modem telemetry antenna for VIS $\ldots \ldots \ldots$

$6 B$. Photograph showing GPS antenna for VIS $\ldots \ldots \ldots \ldots \ldots \ldots \ldots \ldots \ldots \ldots \ldots \ldots \ldots \ldots$

7A. Photograph of the GPS antenna for SPT and tower for solar panels and telemetry antennas . . . . . . . . . . . . . . . . . . . . . . . . . 5

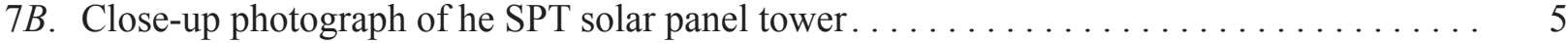

8, Photograph of SDA Z-12R GPS receiver, seismic electronics, and Freewave radio modem 6

9. Photograph of VIS Z-12R GPS receiver, radio modem, seismic and tiltmeter electronics . . 6

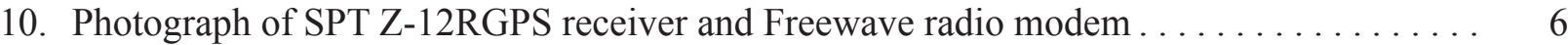

11. Close-up photograph showing the charge/load controller for the solar power system . . . . 6

12. Photograph showing Z-12R, Dell NT workstation, base station, and master radio

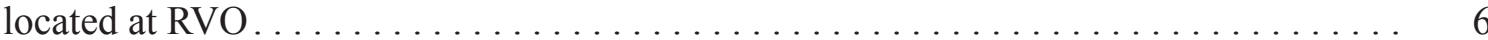

13. Photograph of SDA GPS antenna. The top of the conical antenna cover is visible above a shield constructed to reduce strong GPS multipath signals at the site . . . . . . .

14. Block diagram of GPS data flow to the NT workstation $\ldots \ldots \ldots \ldots \ldots \ldots \ldots$

15. Diagram showing GPS network data stream with radio modems . . . . . . . . . . . . 9

16. Photograph of radio modem antenna for SDA, VIS, and SPT GPS stations . . . . . . . . . 9

17A. Photograph showing rear and front panels of the DGR-115R Freewave radio modem that is designed for protected environments $\ldots \ldots \ldots \ldots \ldots \ldots \ldots \ldots \ldots \ldots \ldots \ldots$

$17 B$. Photograph showing rear and front panels of the DGR-115W water-tight Freewave radio modem . . . . . . . . . . . . . . . . . . . . . . . . . . . . 9

18A. Schematic of backup power station $\ldots \ldots \ldots \ldots \ldots \ldots \ldots \ldots \ldots \ldots \ldots \ldots \ldots \ldots$

18B. Photograph of the Trace DR1512E charger/inverter $\ldots \ldots \ldots \ldots \ldots \ldots \ldots \ldots \ldots \ldots$

$18 C$. Photograph showing close-up view of the Trace system monitoring meter. . . . . . . . 10

18D. Photograph of deep-cycle batteries located in shelter just outside computer/instrument

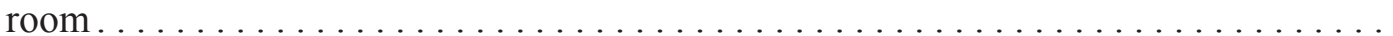

19. Photograph showing type $\mathrm{N}$ male connectors for GPS antenna cables and BNC male connectors for radio antenna cables. A female BNC to male type $\mathrm{N}$ adapter was required for use of the radio antenna cable with Freewave radio modems . . . . . . . . .

20. Schematic of components at each remote GPS station $\ldots \ldots \ldots \ldots \ldots \ldots \ldots \ldots \ldots$

21. Photograph of SS standoff used in the testing of vertical displacement of the rover GPS antenna . . . . . . . . . . . . . . . . . . . . . . . . . . 
22. Graph showing low Q-screen capture of plot from 3d tracker showing the onset

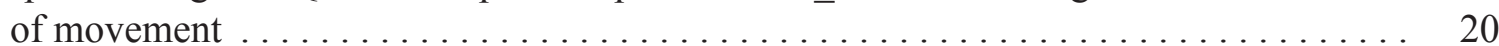

23. Graph of high Q-screen capture of plot from 3d_tracker showing offset very close

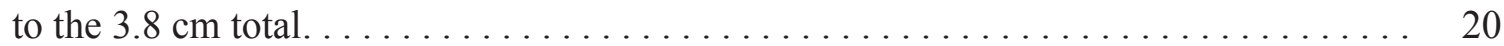

24. Seven-day plot of height for short baseline test. Plot A is for the high Q solutions

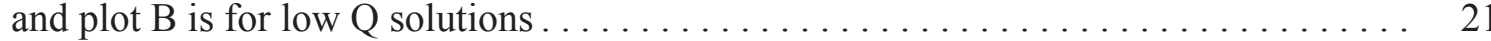

\section{Conversion Factors}

\begin{tabular}{lcl}
\hline \multicolumn{1}{c}{ Multiply } & By & To obtain \\
\hline meter $(\mathrm{m})$ & 3.281 & foot \\
kilometer $(\mathrm{km})$ & 0.6214 & mile \\
centimeter $(\mathrm{cm})$ & 0.3937 & inch
\end{tabular}





\title{
The Rabaul Volcano Observatory Real-Time GPS Upgrade
}

\author{
By Elliot Endo
}

\section{ABSTRACT}

In January 2000 the U.S. Geological Survey installed a real-time GPS monitoring upgrade for the Rabaul Volcano Observatory GPS network. The upgrade included new radio modem telemetry, a computer system, backup power system, and real-time GPS monitoring software. The Rabaul Volcano Observatory GPS network consists of the reference station RVO located at Rabaul Volcano Observatory, the VIS station located at Vulcan, the SDA station located at Matupit Island, and SPT located at Sulphur Point less than 1500 meters from the central vent of Tavurvur. Real-time GPS software collects data from remote receivers once every 10 seconds. 30-second epoch, 24-hour long RINEX files are created for post processing. Real-time GPS program $3 \mathrm{~d}$.tracker ${ }^{\mathrm{TM}}$ processes data once every 10 seconds. Several result plots are available via the 3d_tracker interface. Baseline lengths for GPS processing were $6.1 \mathrm{~km}$ for SDA, 7.7 kilometers for SPT, and 8.7 kilometers for VIS. The U.S. Office of Foreign Disaster Assistance provided funding via Volcano Disaster Assistance Program, which is jointly funded by the U.S. Geological Survey. Volcano Hazards Program.

$$
{ }^{\text {тм }} \text { Trade mark XYZ's of GPS }
$$

\section{PART I. OVERVIEW}

\section{Introduction}

In January 2000 the U.S. Geological Survey (USGS) Volcano Disaster Assistance Project, with funding from the U.S. Office of Foreign Disaster Assistance (OFDA, part of USAID), installed a real-time GPS upgrade for the Rabaul Volcano Observatory (RVO) in Papua New Guinea (PNG) for the purpose of providing RVO scientists with real-time volcano deformation information. The 2000 upgrade corrected deficiencies in the original system, which was installed in 1996. The cornerstone of the upgrade is a new epochby-epoch real-time GPS positioning program called HYDRA (renamed 3d_tracker in 2001). $3 \mathrm{~d}$ tracker is a product of XȲZ's of GPS and Condor Earth Technologies, Inc. (CETI) 3d tracker was released in the spring of 1999 and first installed for a USGS GPS network in Long Valley caldera, California. Other components in the upgrade are: a dual-processor Pentium III NT workstation, Geodetic Base Station Software (GBSS), radio modems, and a charger/inverter system for backup power. GPS receivers, GPS antennas and mounts, instrument shelters, solar panels, and power control systems installed in 1996 were used in 2000. New deep cycle batteries were purchased for 2 sites that did not have the required $400 \mathrm{amp} /$ hour capacity. 
The project started in mid-October 1999 with the initial procurement phase. Known project requirements like the $3 \mathrm{~d}$ tracker software, radio modems, and computer were ordered. RVO was contacted for technical information about the status of GPS equipment. In late November a USGS. geophysicist (E. Endo) traveled to Rabaul to make a technical assessment and to determine accurate hardware requirements for the real-time GPS upgrade. The second phase of procurement took place in December, 1999. In late December, 3d_tracker software was delivered. The NT workstation was set up, software loaded, and the system tested at CVO until a few days before shipment of equipment to Papua New Guinea on January 7, 2000, via DHL. With assistance from the U.S. Embassy in Port Moresby, the shipment of equipment arrived intact on January 20. E. Endo departed Vancouver, WA on January 22 and arrived in Rabaul on January 24. By January 31, the NT workstation, base station radio modems and antennas, base station GPS receiver at RVO, and remote GPS receivers and radio modems at all three remote sites were installed and operational. On February 3 the charger inverter system was installed and on February 7 the realtime GPS system was moved over to the backup power charger/inverter system. E. Endo departed Rabaul on February 9.

Project participants included Gene Iwatsubo from CVO who assisted in procurement and shipping. Other project participants from RVO were Steve Saunders, John Bosco, Titus Tepen, and John Nohou.

\section{Location and Brief Description of Rabaul}

Rabaul is located in East New Britain Province on the island of New Britain in Papua New Guinea (154 degrees E and 4 degrees S latitude, Figure 1). Rabaul volcano is just one of more than a dozen active volcanoes in PNG that are monitored by the Rabaul Volcano Observatory. Rabaul volcano is a caldera approximately $10 \mathrm{~km}$ by $15 \mathrm{~km}$ with two eruption centers, Vulcan and Tavurvur. Both centers erupted in 1937 and 1994. The 1937 eruption killed more than 500 residents of Rabaul. A long public awareness effort by RVO during Rabaul's

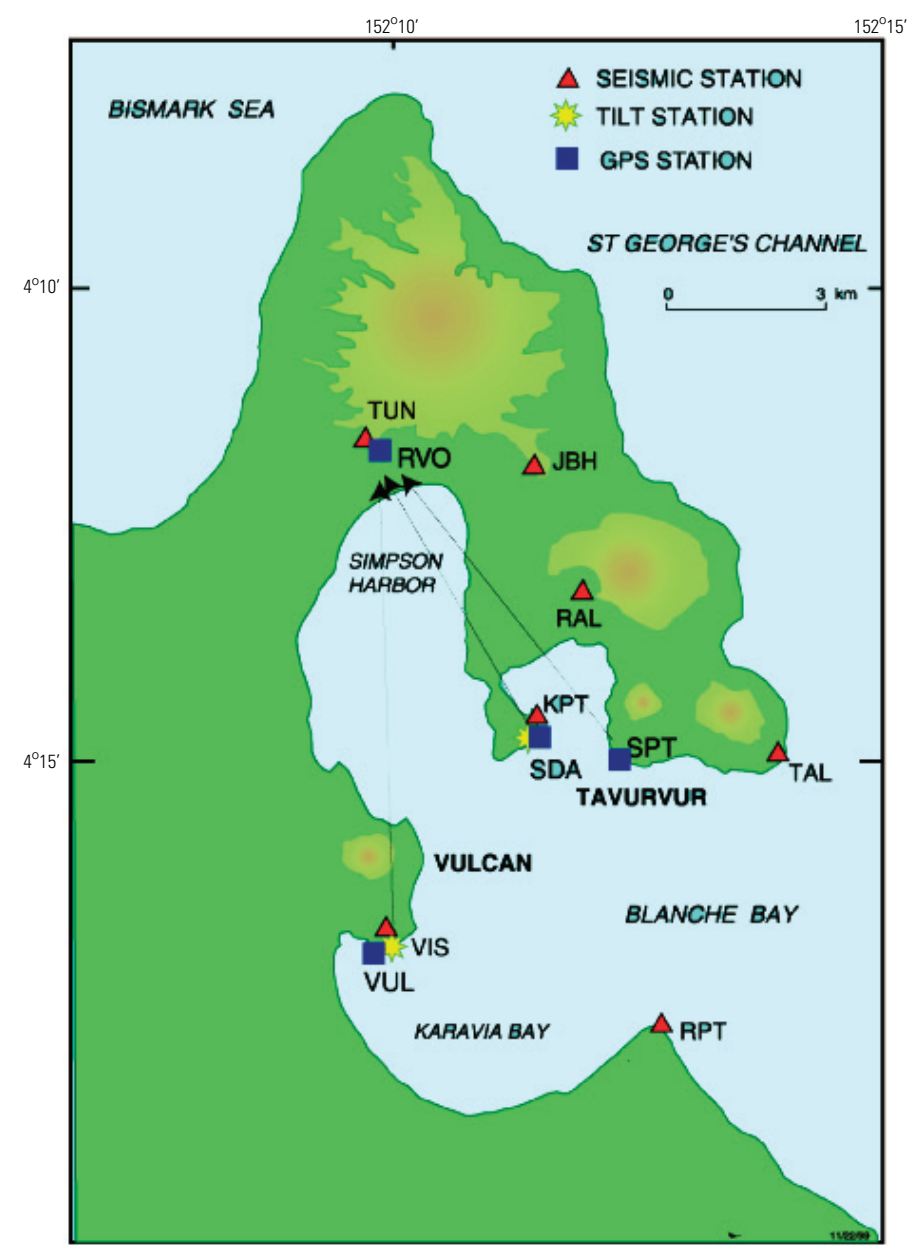

Figure 1. Map of the Rabaul caldera area with GPS and seismic stations shown as square and triangle symbols respectively. The 1994 eruption took place at Vulcan and Tavurvur.

more than 20 years of unrest averted similar loss of life in 1994. Of great concern is the possibility of a large caldera forming event, hence Rabaul is the best monitored volcano in PNG. Rabaul, with its excellent harbor facilities, is also the sea gateway for East New Britain. Rabaul Volcano Observatory is a branch of the Geological Survey Division of the Department of Mining and is staffed by approximately 19 PNG scientists and technical support staff.

\section{The 1996 GPS Network}

Following the eruption of 1994, substantial aid was provided by AusAID via the Australian Geological Survey Organisation (AGSO) to repair facilities at RVO and to replace or upgrade RVO's monitoring capability. In 1996 were Global Positioning System (GPS) receivers 
were installed for the purpose of 3-d monitoring of changes in the earth's topography that are related to the inflation or deflation of volcanoes (volcano deformation). While not the most precise method for volcano monitoring, GPS technology is the only standard surveying method that has the capability to provide a 3-d vector for displacement. Electronic distance measurement (EDM) devices provide 2-d measurements, precise leveling provides only elevation changes, and tilt monitoring devices provide only a direction and magnitude of local ground tilt. Four GPS receivers delivered in 1996 were intended for a real-time GPS positioning network.

The original real-time GPS network utilized internal GPS receiver processing to produce a differential position (CPD or carrier phase differential processing). To achieve that, carrier phase information in the form of Ashtech DBEN messages had to be transmitted from a base station GPS receiver (also known as a reference site). This base station was the RVO GPS station (Figure 2). The remote GPS receiver used received DBEN messages for processing and put a CPD solution out one of the Z-12R ports to be transmitted back to RVO for collection and plotting by a PC. CPD solutions were basically L1 only or single frequency solutions without an ION (ionosphere) correction or troposphere modeling.

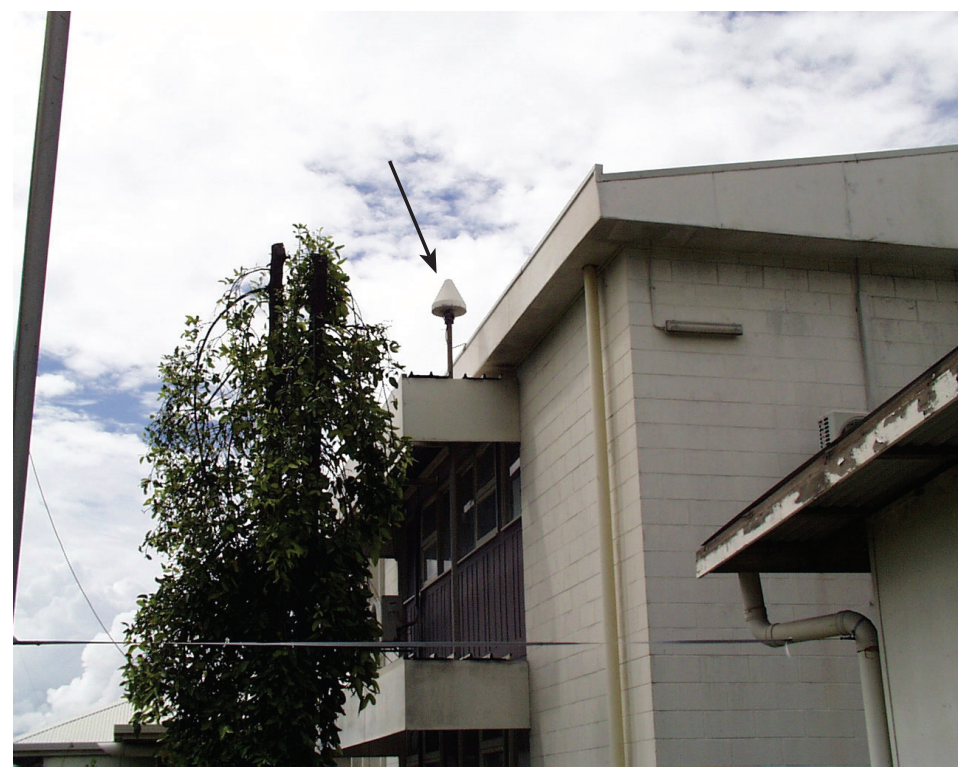

Figure 2. The antenna for the RVO GPS base station located outside the main RVO building.
It is also suspected that internal processor capability limited the ambiguity resolution capability of the internal firmware and its ability to handle data from more than 9 satellites. The CPD method was probably not suitable for the 6.1 to $8.7 \mathrm{~km}$ baseline distances from RVO. There was also no capability to provide easy-to-interpret plots of changes in position in real-time. While it cannot now be confirmed, there may have been a serious problem with the telemetry scheme that could not handle larger packet sizes associated with a high number of satellites visible. The major problem is the nature of GPS results. GPS results are inherently noisy for many reasons such as troposphere effects (humidity), ION effects, multi-path, geometry, and satellite orbital errors. Some kind of statistical treatment of data is required to achieve high accuracy and confidence in results.

Remote GPS stations established in 1996 (Figure 1) were located with other geodetic and seismic monitoring sites. GPS equipment for the SDA station (Figure 3) on Matupit Island was located in a concrete tile church steeple and the choke ring antenna mounted on the concrete roof of the tower. Concrete tile vaults were built for the Vulcan (VIS, figure 4) and Sulphur Point (SPT, figure 5) stations and co-located with electronic tiltmeters. Platforms on towers about 7-8 $\mathrm{m}$ high were erected for VIS (Figures 6a) and SPT (Figures 7a, 7b) for solar panels and radio telemetry antennas (Figure $6 \mathrm{~b}$ ). 12-14 cm diameter pipe embedded in concrete 1-2 m was used for GPS antenna masts at VIS and SPT. Of 3 stations, only SPT offered direct line of sight with RVO in December 1999. The radios installed in 1994 for GPS telemetry used frequencies close to $455 \mathrm{MHz}$ and put out about 2 watts of RF power.

\section{GPS Receivers}

GPS receivers used for the project were Ashtech Z-12R's (rack mount versions of the Z-12, Figures 8, 9, 10, 12). Three remote receivers have no memory for storage. The Ashtech Z-12R receivers are dual-frequency P-code tracking receivers 


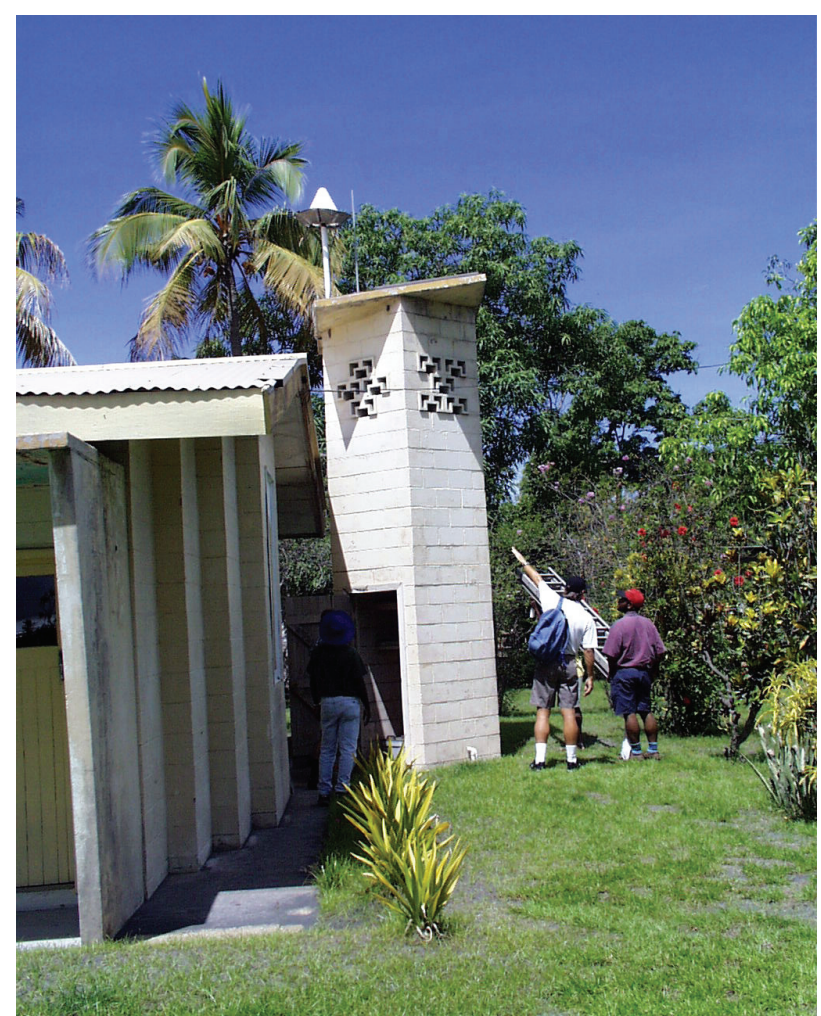

Figure 3. The SDA GPS station on Matupit Island. GPS and seismic electronics are located at the base of the church steeple. Note GPS antenna at the top (coneshaped cover).

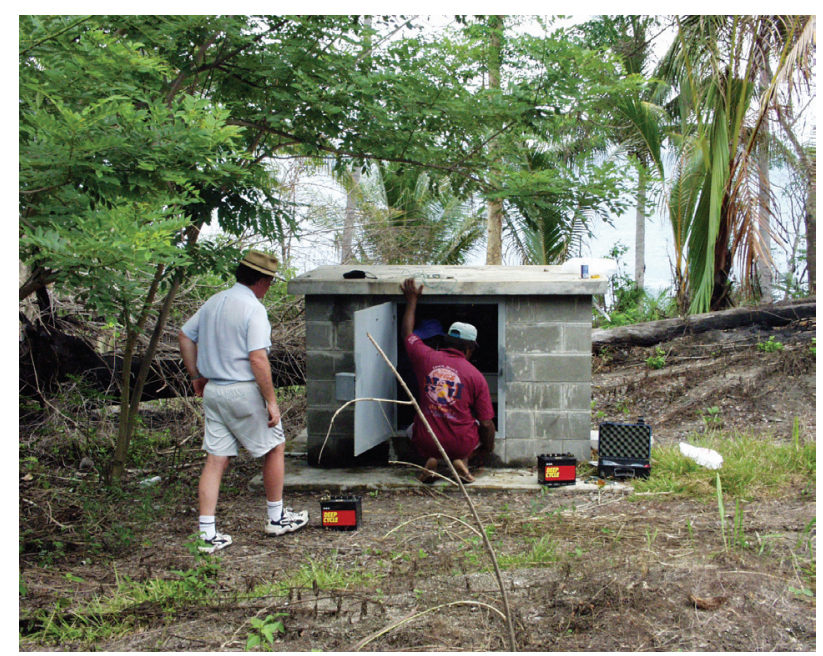

Figure 4. The VUL/VIS vault for GPS receiver tiltmeter and seismic electronics. VIS = GPS station name and VUL = seismic station name.

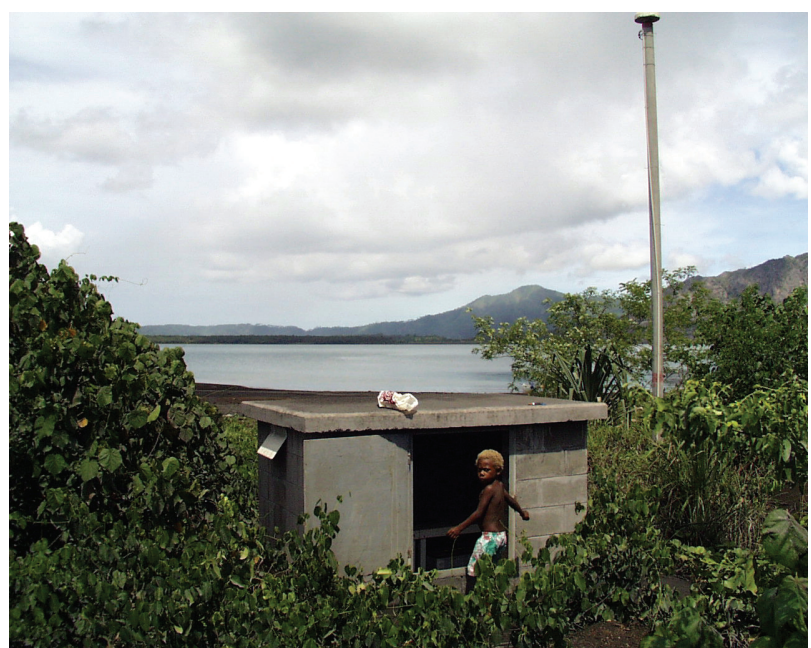

Figure 5. The SPT vault. GPS antenna on far right.

that consume approximately 12 watts of power. In December 1999, firmware for the receivers was upgraded to handle the rollover in GPS time. At this time hardware for radio telemetry and control was removed from each of the receivers and original Ashtech DB9 RS-232 connections restored. In 2002 Magellan/Ashtech (Thales) placed the Z-12 on a phase out list.

GPS receivers were supplied with choke-ring antennas and cone-shaped covers (Figures $6 \mathrm{~b}$ and 13). An additional shield beneath the antenna was rigged to reduce possible multi path effects for satellite signals.

\section{Components of the Real-Time GPS Upgrade}

\section{Computer}

The computer selected for the Rabaul realtime GPS upgrade was a Dell 410 PIII dualprocessor $450 \mathrm{MHZ}$ system with: 256 megabytes of memory, two 9.1 gigabyte ultrawide/ultrawide LVD SCSI drives, a 32 megabyte memory Viper video card, onboard Ethernet capability, 3 1/2" floppy drive, 40x CD reader, and an Equinox RS-232 16 port card. A 6X CD writer was added as an external device. The computer was configured as an NT workstation (Figure 12). 

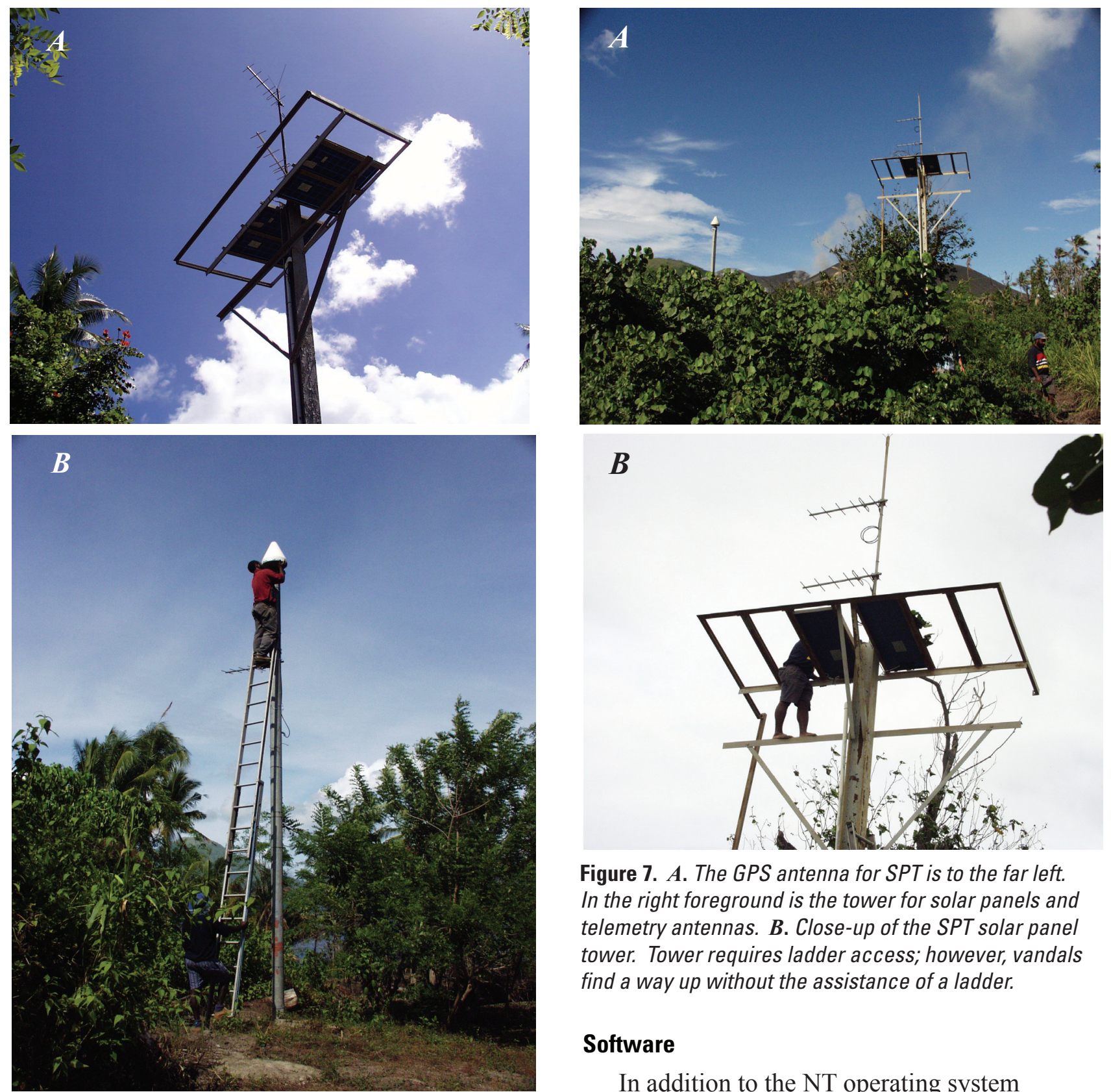

Figure 7. $A$. The GPS antenna for SPT is to the far left. In the right foreground is the tower for solar panels and telemetry antennas. B. Close-up of the SPT solar panel tower. Tower requires ladder access; however, vandals find a way up without the assistance of a ladder.

\section{Software}

In addition to the NT operating system Figure 6. $\boldsymbol{A}$. Solar panels and radio modem telemetry antenna for VIS. $\boldsymbol{B}$. The GPS antenna for VIS. The seismic telemetry antenna is located near foot of Titus Tipen. version 4.0 (Service pack 6) the following software was installed on the Dell 410:

GBSS - Geodetic Base Station Software

3d_tracker Real-time deformation monitoring software

PKZip

Equinox drivers

CD Writer software

Adobe Photoshop LE

Disk-keeper (removed)

GBSS is a program supplied by Magellan/ Ashtech. Its main purpose is to provide 


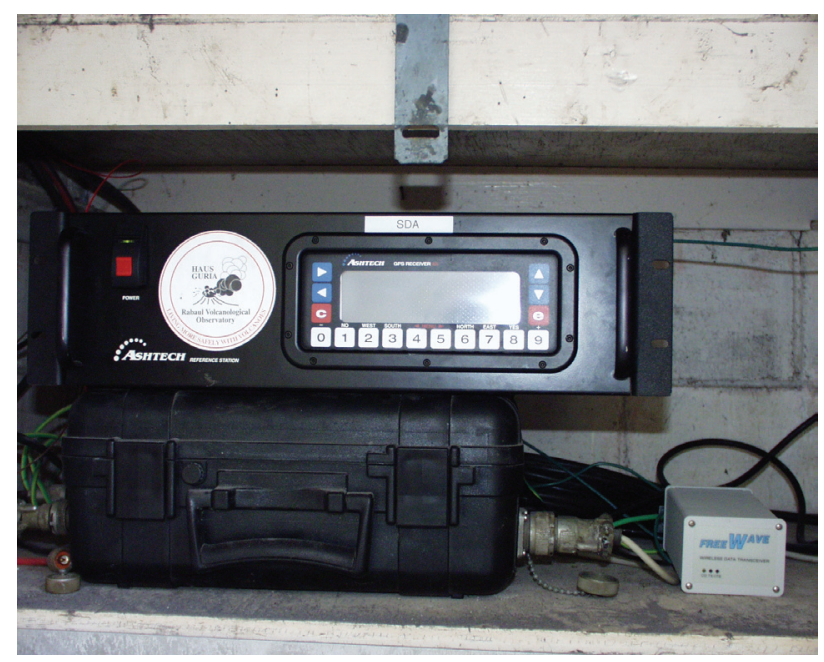

Figure 8. The SDA Z-12R GPS receiver, seismic electronics, and Freewave radio modem.

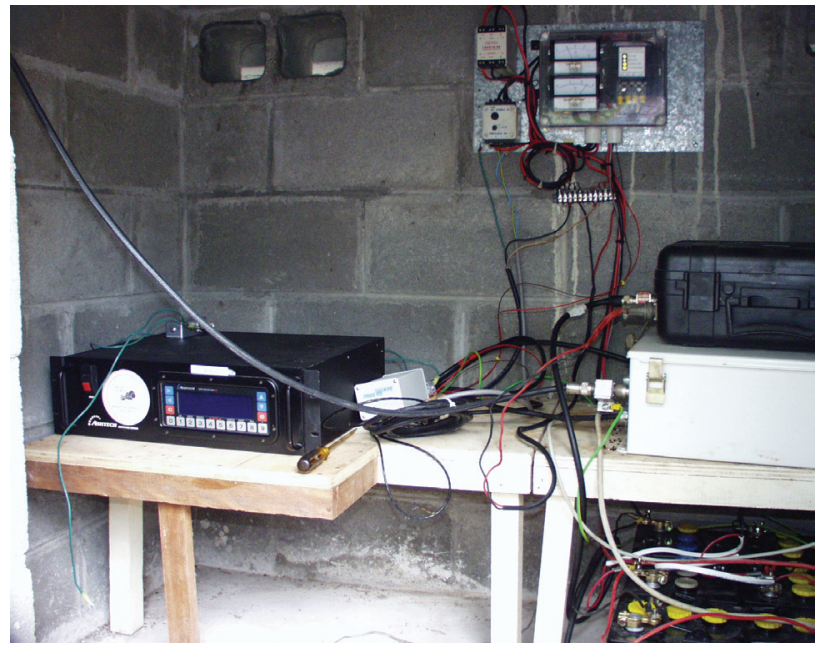

Figure 9. The VIS Z-12R GPS receiver, radio modem, seismic and tiltmeter electronics. Note bank of batteries beneath shelf on the right.

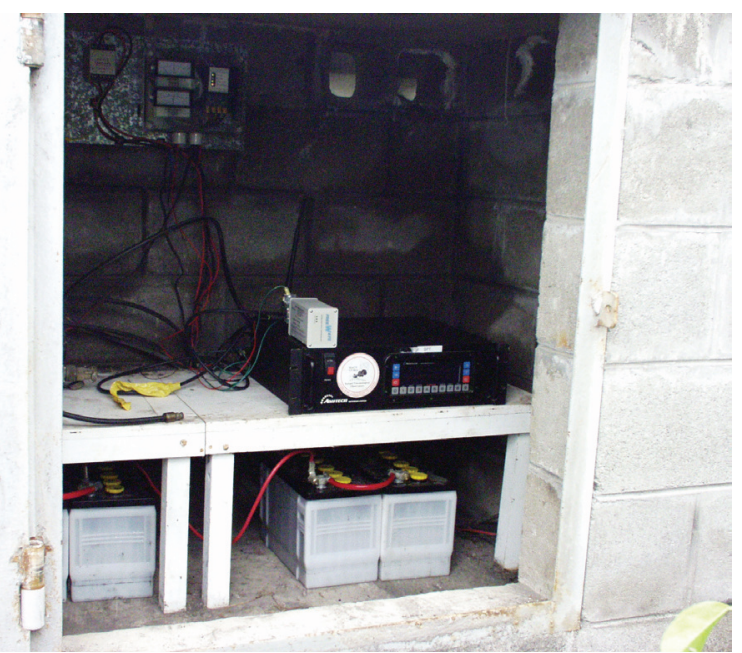

Figure 10. The SPT Z-12R GPS receiver and Freewave radio modem.

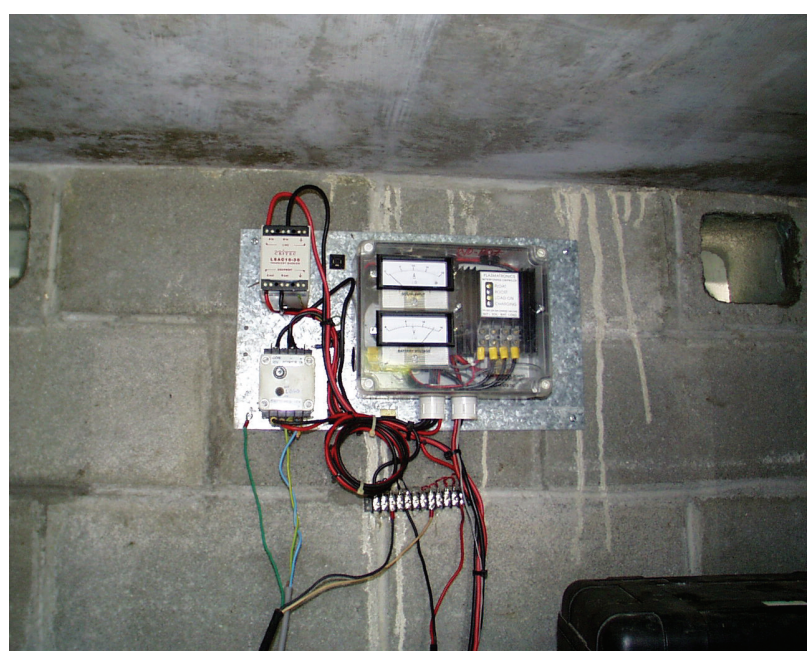

Figure 11. Close-up of the charge/load controller for the solar power system.

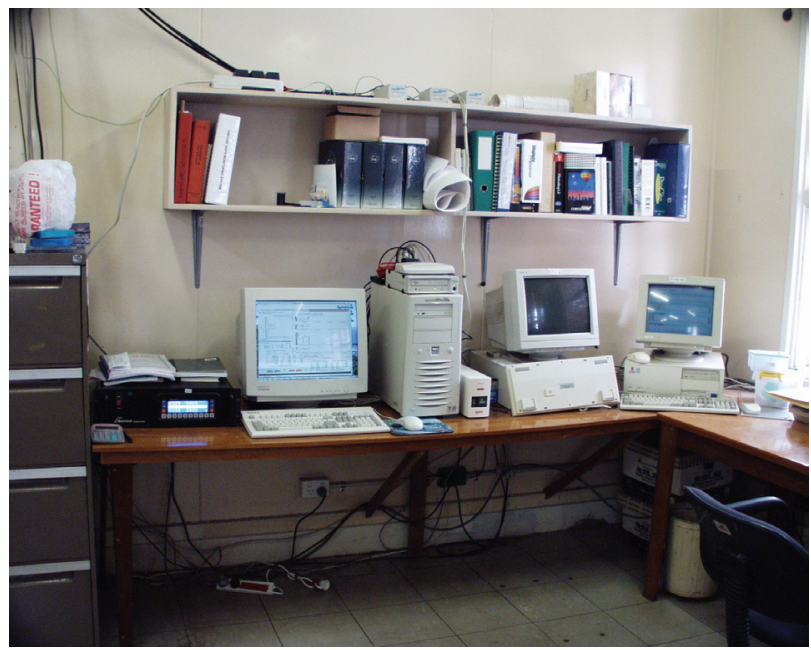

Figure 12. The Z-12R located at RVO (next to file cabinet). To the right of the GPS receiver is the Dell NT workstation used for GPS data collection and read-time GPS processing. Base station and master radio modems are located on the top shelf.

communication with a Magellan/Ashtech GPS receiver for the purpose of collecting carrier phase data at a user specified rate. In addition to its ability to collect data from remote receivers, GBSS has a real-time interface (Figure 14) that allows it to hand off data to another program. GBSS has a user interface that provides information on the GPS receiver status and the status of data collection. Each GPS station requires a separate GBSS process and has to be configured for a baud rate that matches the radio modem and GPS receiver baud rates. GBSS is normally configured to write 24-hour Ashtech binary or RINEX format files once a day. GBSS 
will automatically decimate data for the purpose of daily 24-hour files. For RVO, 10-second data that is used for the $3 \mathrm{~d}$ tracker real-time GPS program is decimated to 30 -second epochs. A hardware key is required for operation. There is no restriction on the number of GBSS processes installed on a computer. The USGS donated a hardware key to RVO. A complete manual for GBSS was given to RVO. In 2002 the Dell 410 was replaced with a custom built system based on an Asus dual-processor PIII motherboard.

The 3d_tracker is the epoch-by-epoch processing program that produces real-time triple difference solutions for position. Like GBSS, 3d_tracker is a product of XYZ's of GPS and is supplied by Condor Earth Technologies, Inc (CETI). CETI is an authorized system integrator for XYZ's of GPS and Magellan/Ashtech. 3d tracker at RVO is configured to process solutions once every 10 seconds. $3 d_{\text {d tracker is capable }}$ of very high accuracy or very fast response, but not both because of the nature of the Kalman

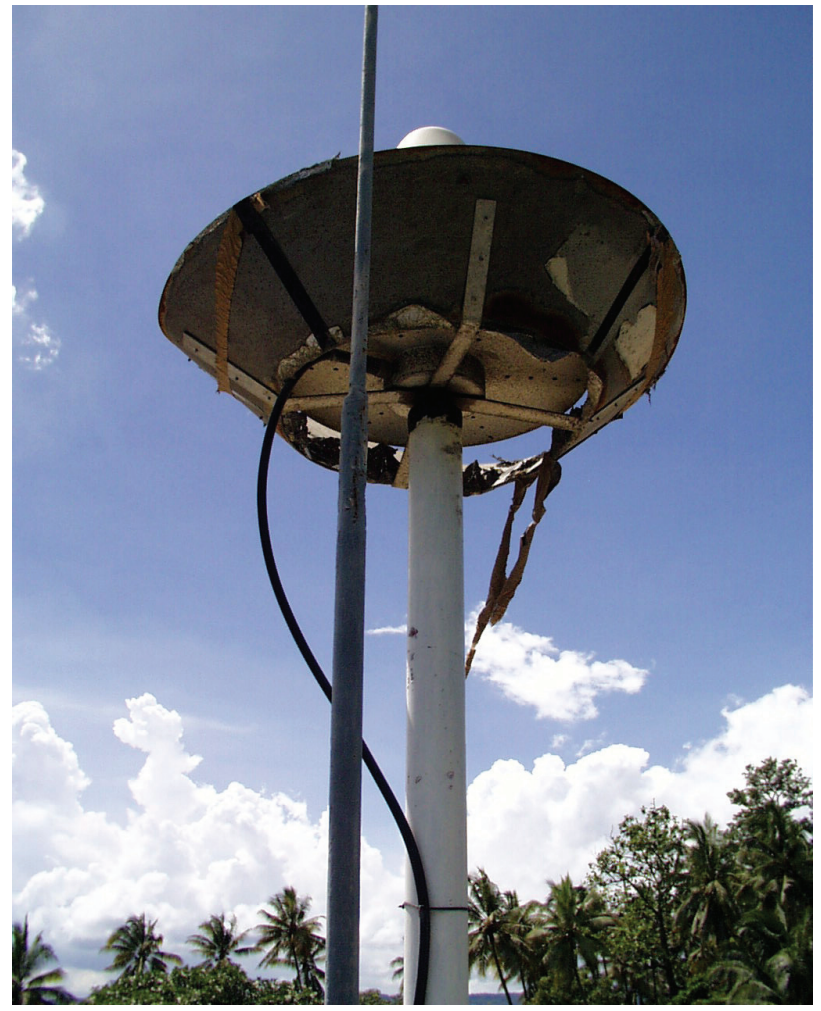

Figure 13. The SDA GPS antenna. The top of the conical antenna cover is visible above a shield constructed to reduce strong GPS multipath signals at this site. The multipath problem may result from several solar panels located just outside the lower view of the photograph. filter technique (statistic characterization of an estimation problem). A detailed explanation of the Kalman filter theory and method used for $3 \mathrm{~d}$-tracker is beyond the scope of this report. See appendix for further discussion of 3d_tracker. To get around this problem, three processes for 3 remote GPS stations at RVO have been configured for high accuracy over a 24-hour period. This is the low Q solution. Two 3d tracker processes have been configured for fast response. Low Q solutions have covariances at the $\mathrm{mm}$ level. High Q solutions have $5 \mathrm{~mm}$ or more covariances. 3d_tracker requires a hardware key for operation.

The Kalman filter method could be described as a recursive averaging filter. In the case of 3d_tracker, it has characteristics similar to a low pass filter and like any filter has properties that impact the final result. In 3d tracker, low Q is like a very restrictive low pass filter. The result is sluggish response to changes. High Q results in quick response but also results in more noise. A complete manual for $3 \mathrm{~d}$ _tracker is provided for RVO.

\section{Telemetry}

For the purpose of communicating with remote GPS stations, pairs of spread-spectrum frequency-hopping radio modems from Freewave Technology were used (Figure 15). Radio modems used at Rabaul were configured to use the PNG approved Australian band (915-928 $\mathrm{MHz}$ ) for spread spectrum applications. Radio modems were connected to port A of the Z-12R GPS receiver via a DB9 female connector. MAXRAD BMOY89085 9 dbi gain yagi antennas were used for both remote sites and base station sites. The exception was the SPT installation where an existing yagi antenna and cable were utilized. For base station radio modems and the SDA site, LMR400 low loss rf cable was used to connect antennas to radio modems (Figure 16). Antenna cable runs were kept under $30 \mathrm{~m}$ to avoid signal loss. Remote site radio modems were powered by $12 \mathrm{vdc}$ from the solar power system. Base station radio modems were powered by Freewave supplied dc power supplies plugged into a step-own voltage controller. Remote sites 
were supplied with DGR-115W water-tight models of the Feewave radio modems and the base station with the DGR-115R professional model (Figure 17a and 17b).

\section{Backup Power System}

To help prevent interruption of $3 d$ _tracker processing, a charger/inverter system was selected for intermediate term (10-12 hours) backup power. A Trace DR1512E modified sine wave system was selected (Figure 18a, b, c, d). The Trace DR1512E is rated at 1500 watts and operates on 230-240 VAC $50 \mathrm{~Hz}$. The charger/ inverter was wired in to a dedicated $15 \mathrm{amp}$ circuit and normally supplies power from a line that comes in from the local power grid. When grid power fails, the charger/inverter switches over to inverter mode in 32 milliseconds. At present, two $125 \mathrm{amp} / \mathrm{hr}$ deep cycle 12 volt batteries provide DC power for the inverter mode. When power is restored the DR1512E charges the deep cycle batteries and also provides line power. A Trace TM500 monitor provides remote control and monitoring of the charger/ inverter system. To reduce impact of 20-40 millisecond charger/inverter switch over response time, a small UPS is used for the NT workstation.

The RVO backup generator is expected to provide the primary power back up and is currently set up to start up automatically in about a minute after grid power failure.

\section{NT WORKSTATION GPS DATA STREAM}

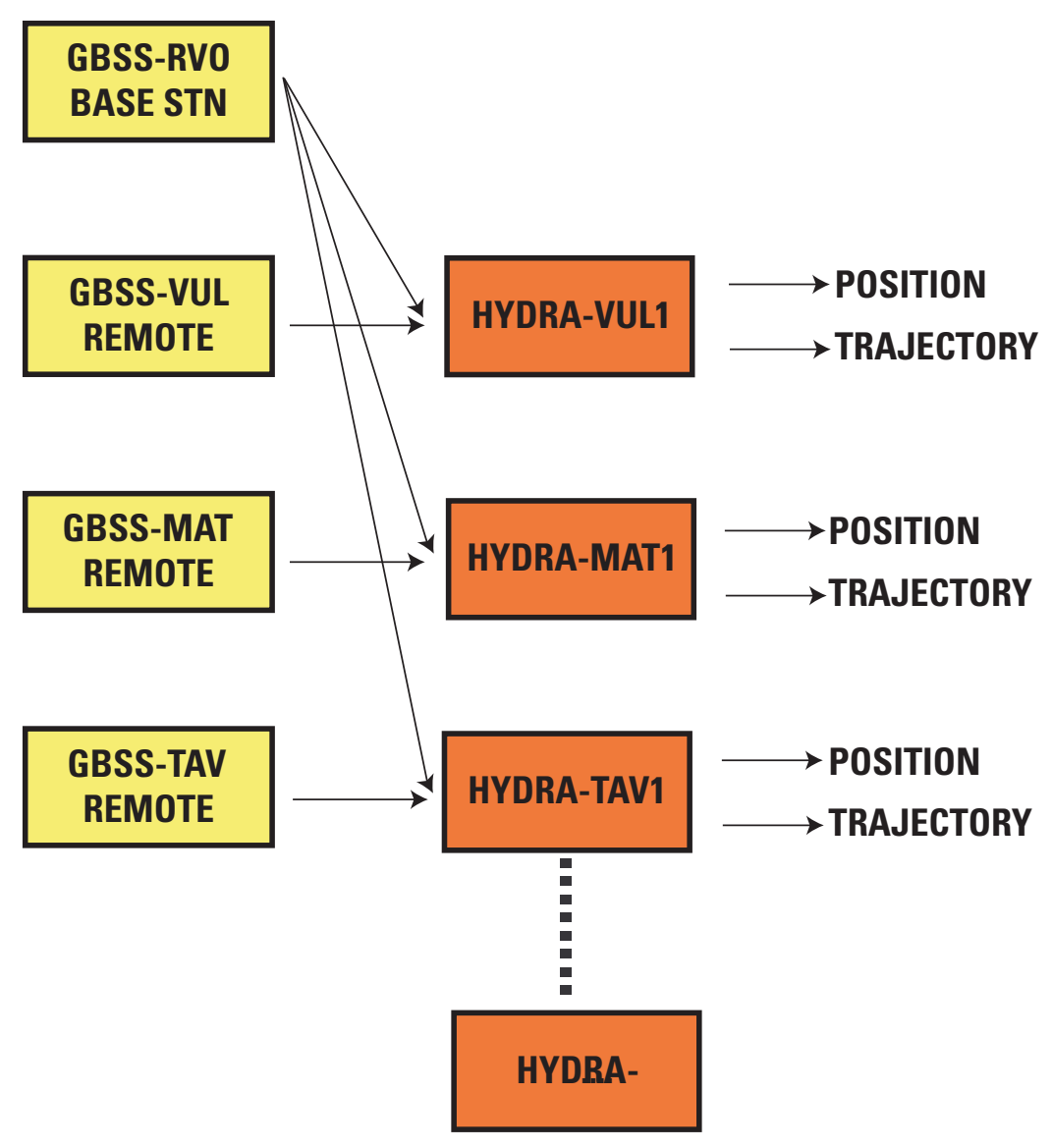

Figure 14. Block diagram of GPS data flow in the NT workstation. 
GPS NETWORK DATA STREAM RABAUL VOLCANO OBSERVATORY

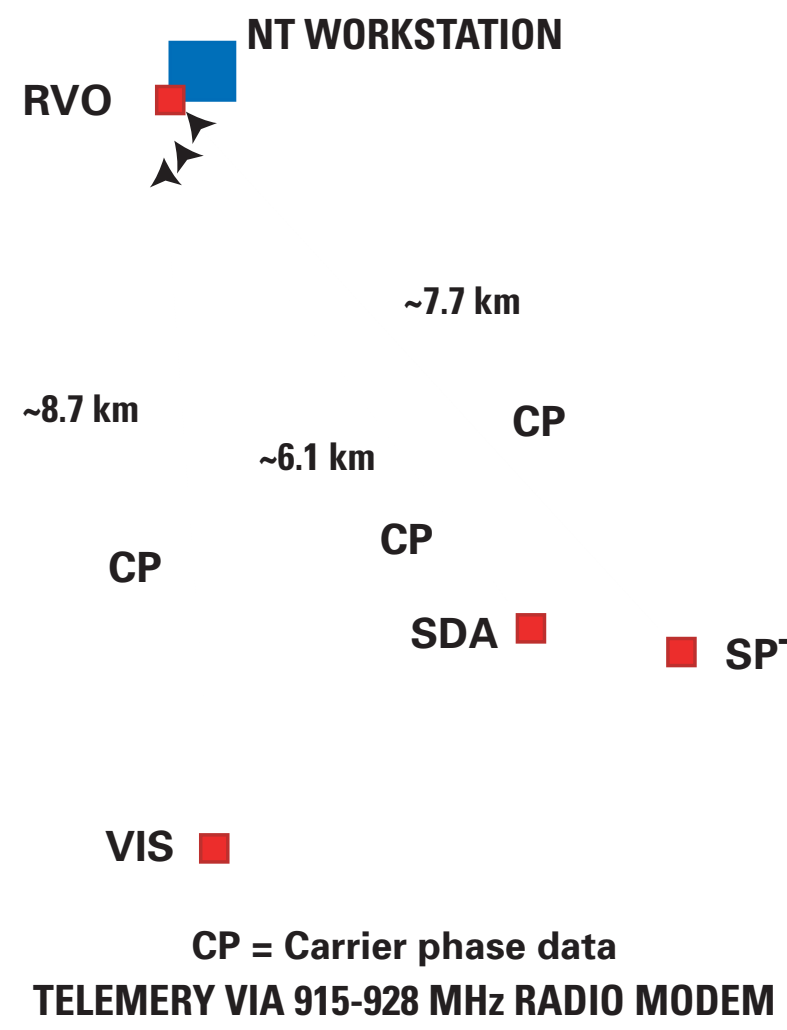

Figure 15. Diagram showing GPS network data stream with radio modems. Map distances from remote stations to RVO are shown.

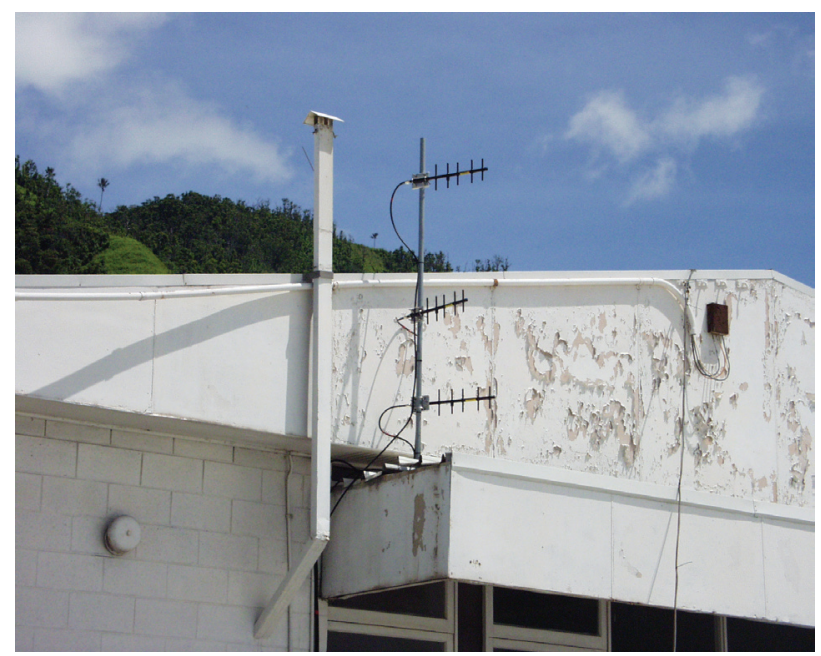

Figure 16. Radio modem antennas for SDA, VIS, and SPT GPS stations.
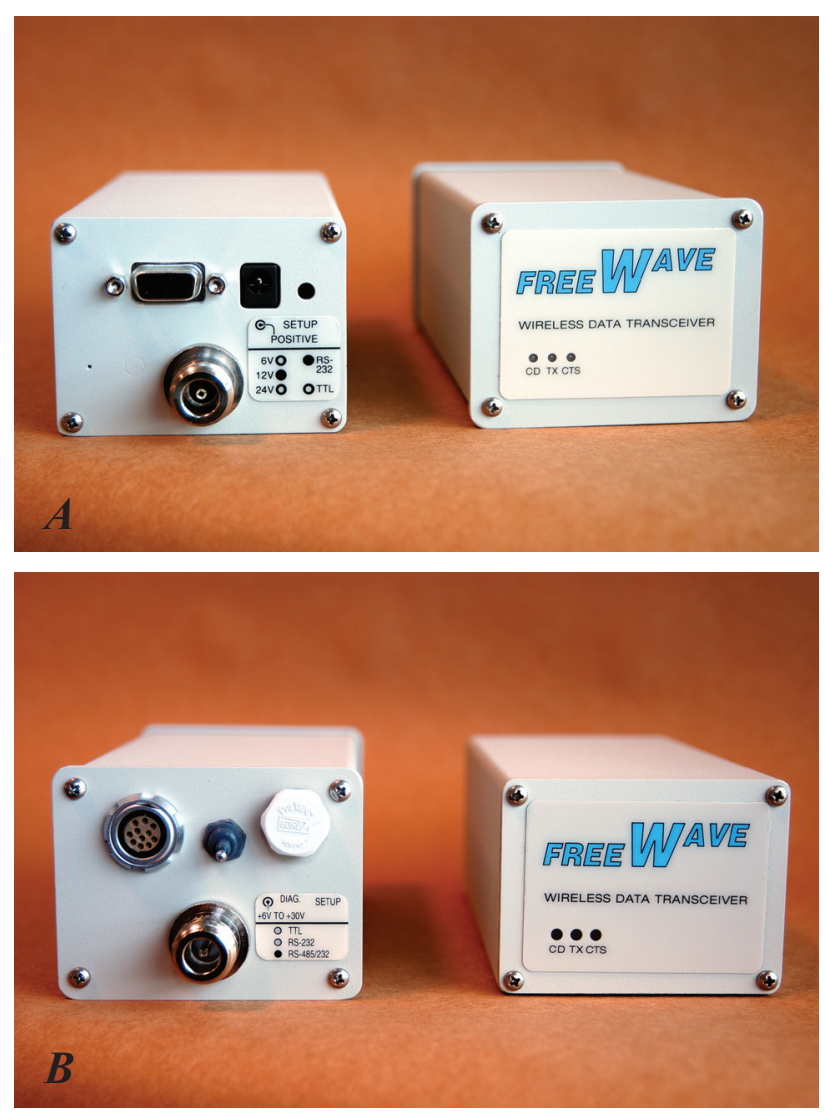

Figure 17. $A$. Rear and front panel view of the DGR-115R Freewave radio modem that is designed for protected environments. $\boldsymbol{B}$. Rear and front panel view of the

\section{Installation}

Installation preparation began at $\mathrm{CVO}$ where required software was installed on the NT workstation in mid-December. Radio modems were configured and tested. The NT workstation was set up for testing and GBSS and 3d tracker software configured for a pair of Z-12 receivers. The system was tested for about 2 weeks before being shipped via DHL on January 7. 420 pounds of equipment was shipped to Rabaul. The first task was to unpack the shipment, set up the NT workstation, and configure GBSS software for collecting GPS data from the RVO base station. The next step was setting up the base station radio modems, antennas, cables, and power. Powering up base station radio modems first provided a means of verifying radio modem connection while at remote sites.

SDA was the first station re-installed on January 27. Existing batteries (2 x $200 \mathrm{amp} / \mathrm{hr}$ truck batteries) were used. New radio modem 


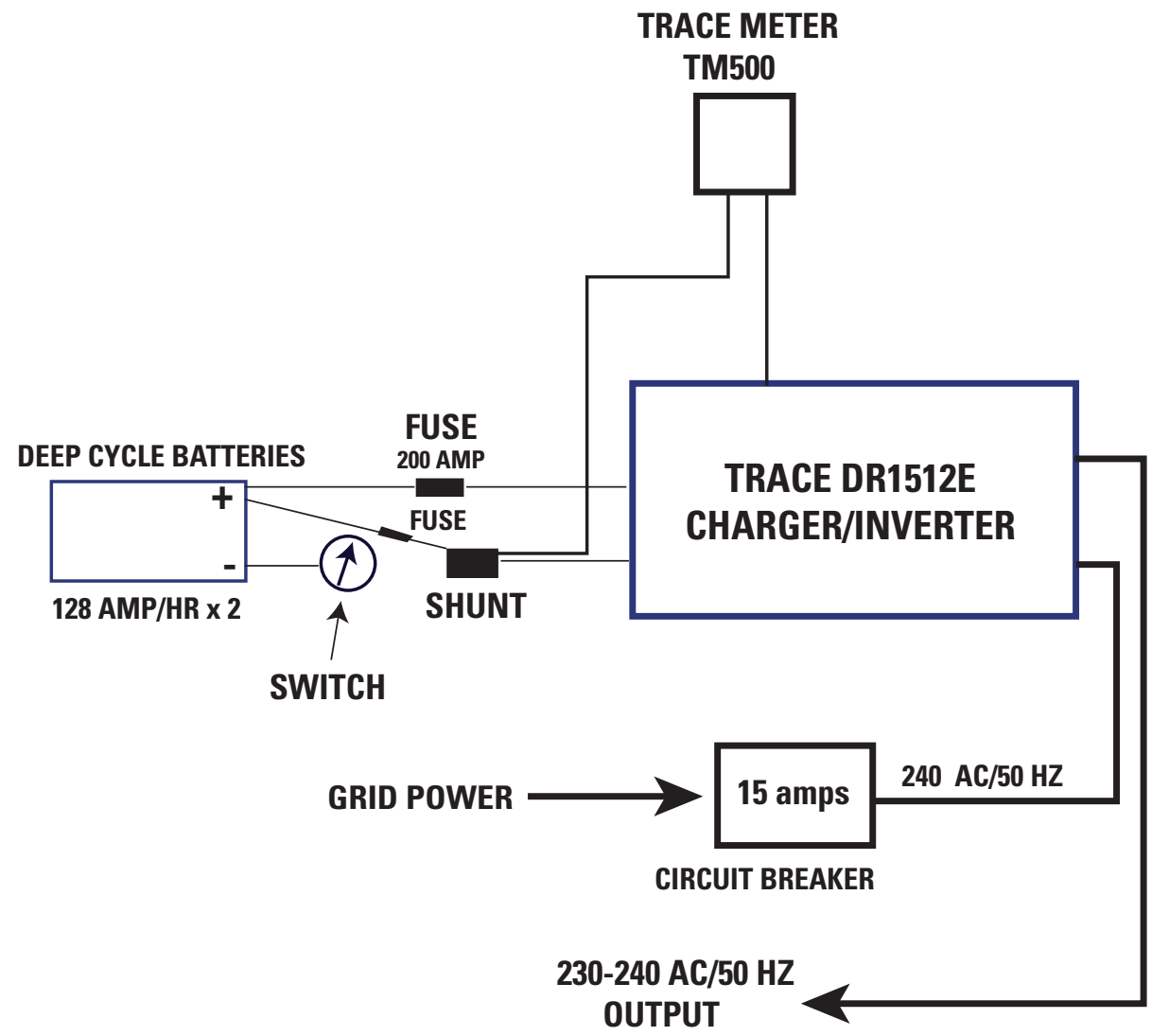

Figure 18A. Schematic for backup power system.

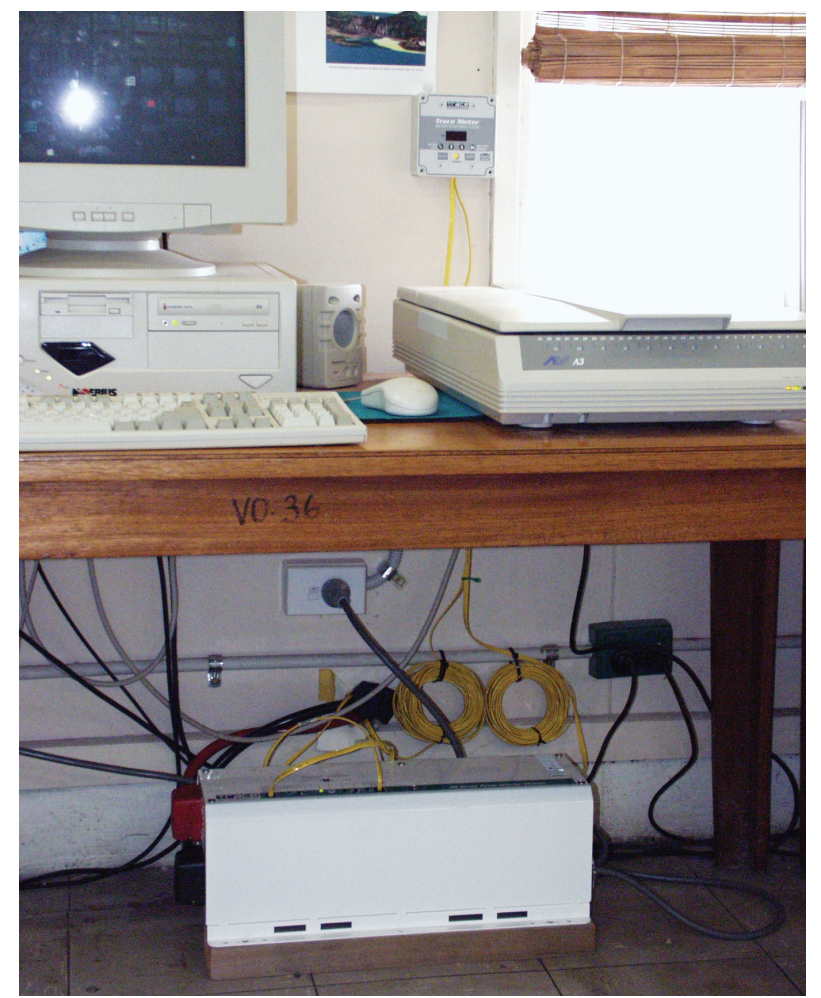

Figure 18B. The Trace DR1512E charger/inverter located beneath the table. The Trace system monitoring meter is at the top-middle.

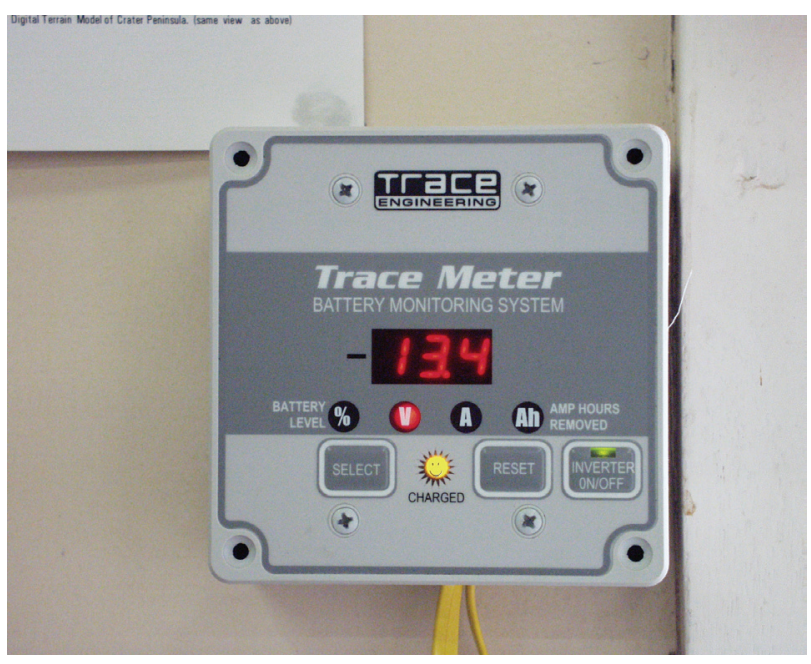

Figure 18C. Close-up of the Trace system monitoring meter. 


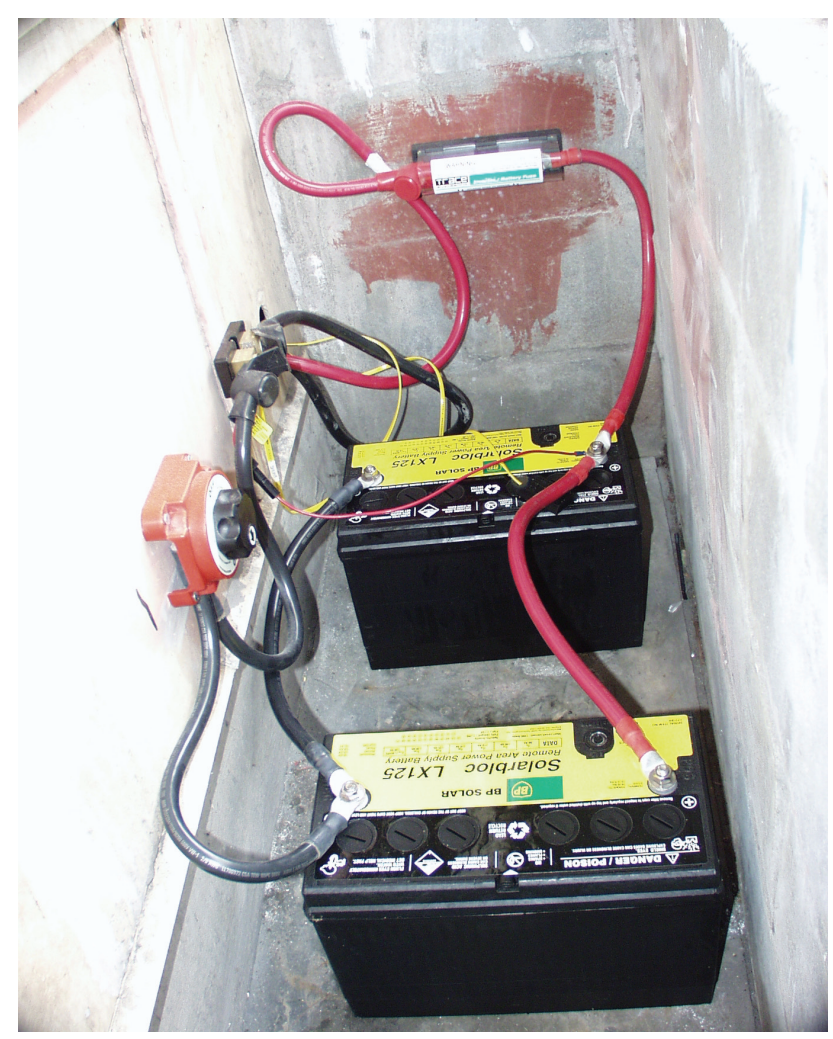

Figure 18D. Deep-cycle batteries located in shelter just outside the computer/instrument room.

antenna cable was used and the antenna was installed on a mast used for tilt meter telemetry. There was no line-of-sight with RVO owing to a mango tree and coconut palms, however we did have a lock on the SDA master radio modem. The next site re-installed was VIS on Vulcan on January 28. Four new $100 \mathrm{amp} / \mathrm{hr}$ deep cycle batteries replaced an existing pair of $65 \mathrm{amp} / \mathrm{hr}$ batteries. A spare antenna cable on the solar panel tower (type $\mathrm{N}$ male connectors) was used for the radio modem yagi antenna. Like SDA there was no line-of-site with RVO. Base station radio modem transmission statistics at RVO indicated a strong signal from VIS and SDA. On January 31, SPT was re-installed. The task required an open boat trip to SPT across Simpson and Greet harbors. Four new deep cycle batteries replaced an existing pair of $65 \mathrm{amp} / \mathrm{hr}$ batteries. A second 60 watt solar panel was installed. Owing to height the existing yagi for GPS telemetry on the solar panel tower could not be removed. The clear line-of-sight and short distance with RVO made it possible to use it as the antenna for the radio modem. The SPT site required BNC (F) to type $\mathrm{N}$ (M) adapter (Figure 19).

After each installation, GBSS and 3d_tracker processing were configured and started. The last piece of hardware to be installed was the Trace charger/inverter. The installation was delayed by the lack of additional deep cycle batteries from the Rabaul Battery Service. A pair of batteries had to be ordered from another source in Lae. On February 7 the real-time system was switched over to the charge/inverter power system. A complete $\mathrm{CD}$ backup of program files and data was done before re-starting GPS programs.

\section{PART II. TECHNICAL DETAILS}

\section{NT Workstation Configuration}

The NT 4.0 operating system came preinstalled from Dell on a 2 gigabyte partition $(\mathrm{C}$ : drive) on a 9.1 gigabyte SCSI ULTRA/ULTRA WIDE LVD drive. Service packs up to 6 were installed at CVO. For reasons never determined, the computer operating system could not be configured for automatic bypass of the logon. A second 9.1 gigabyte drive was configured as the $\mathrm{D}$ : drive and a 7 gigabyte partition on the first drive was configured as the E: drive. Daily (24-hour) Magellan/Ashtech binary files of carrier-phase data are written by GBSS processes

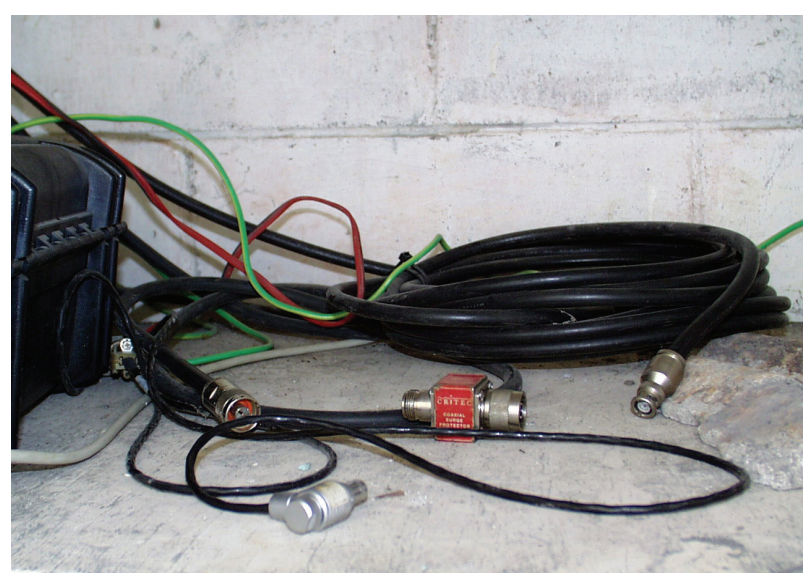

Figure 19. The original installation of GPS receivers and radio telemetry systems used type $N$ male connectors for the GPS antenna cable and BNC male connectors for the radio antenna cable. A female $B N C$ to male type $N$ adapter was required for use of the radio antenna cable with Freewave radio modems. 
to the PRIMARY folder on the E: drive. RINEX files are written to the SECONDARY folder. Magellan/Ashtech binary files has to be selected for the RINEX conversion. The Magellan/ Ashtech directory or folder structure was selected. Files were organized by month and day. 3d_tracker output, primarily the Kalman filter database, scratch files, and daily position files are written to a $3 d$ tracker.dat folder on the D: drive. The present version of $3 \mathrm{~d}$ _tracker writes all results to the same folder.

GBSS and 3d_tracker software are located in the Program Files folder of the C: drive. GBSS installed files are located under GBSS0126 and $3 d$ tracker installed files under Ashtech. There are 4 subdirectories or folders for RVO_, SDA_, VIS_, and SPT_. Each contains .ini files for each of the GPS stations. Normally. The .ini files are automatically stored during the configuration process. In the event of a problem with ini files, restore the directory from the Feb. 7, 00 backup CD. GBSS knows the location of .ini files during the connect process.

There is a separate folder or directory for each 3d_tracker process configured. For RVO these are: Sda1, Vis1, Spt1, Sda5, Sptx, Vissdad, and test. The $3 \mathrm{~d}$ tracker folder contains the unaltered install files.

Both computer and monitor had autoswitching for input voltages and input power frequency, and both were operated at 220-240 VAC and $50 \mathrm{~Hz}$.

\section{Base Station Set Up GPS Receiver}

The Z-12R located at RVO required the real-time interface to be turned on. While not required, the baud rate for the A serial port was set for 56kbaud. Settings were "saved" in internal memory so they would be retained during a power failure or when switched off.

\section{Radio Modems}

Three radio modems installed at RVO were Freewave DGR-115R (Figure 17a) units. DGR$115 \mathrm{R}$ radio modems have a DB-9 connector for connection to a computer serial port, a type $\mathrm{N}$ connector for an external antenna, and a 12 VDC connector for power. Radio modems required approximately 1 watt of power. DC adapters supplied by Freewave required 110-120 VAC. A switching step-down transformer was used to provide the required voltage. The DGR-115R radio modems are not in a waterproof case. Radio modems at the base station were configured as "MASTER" and assigned RS232 ports 3-5 on the Equinox port expander. The following radio transmission parameters were used:

$\begin{array}{ll}\text { FreqKey } & \text { see below } \\ \text { Max Packet Size } & 8 \\ \text { Min Packet Size } & 9 \\ \text { Xmit Rate } & 1 \\ \text { RF Data Rate } & 3 \\ \text { RF Power } & \text { see below } \\ \text { Slave Security } & 1 \\ \text { RTS to CTS } & 0 \\ \text { Retry Time Out } & 255 \\ \text { Lowpower Mode } & 0\end{array}$

SDA was assigned FreqKey 5, SPT 1, and VIS 9. SDA and VIS were both configured for maximum rf output power of 9 and SPT 7. All radio modems were set for 19.2 kbaud for communication with GPS receivers and the NT workstation.

Radio Modem Phone Numbers SDA, remote 902-0403, base 901-8710

SPT, remote 902-0402, base 901-8711

VIS, remote 902-0404, base 901-8144

RVO was provided with 1 spare DGR-115R with phone number 902-1918. The VIS remote and base modems were configured to use this spare as a repeater if required. Radio modems were all supplied with Polyphaser IS-B50LNC2-ME surge protectors. Surge protectors were grounded to the overhead cable rack.

\section{Radio Modem Antennas}

MAXRAD 9 dbd yagi antennas (baked enamel finish) were installed on the main observatory building. Antennas were connected to radio modems via Times Microwave (Hutton Communication.) LMR400 low loss cable. The 
cable run was estimated to be about 20-25 meters and accounts for less than $3 \mathrm{db}$ loss of signal. Times Microwave TC-400-NMH connectors were used for all type $\mathrm{N}$ connections.

\section{Backup Power}

The frequent power outages in Rabaul required some form of backup power. At RVO a diesel generator normally starts automatically within a minute after a power failure. Periodically the generator fails to start automatically and requires a manual start. A manual start could take hours depending on the time of day and how soon a power failure is noticed. A small UPS (uninterruptible power supply) has a battery large enough to keep a computer operating for 10-15 minutes. For longer backup power operation a charger/inverter system is required. For Rabaul, a Trace DR1512E (Figures 18a, 18b, 18c, 18d) modified sine wave charger/inverter was selected. The charger/ inverter is similar to a UPS but has the advantage of allowing the user to install as many batteries as required for the application. The modified sine wave model was selected over a pure sine wave unit because of the lower cost and in some cases slightly better efficiency. One disadvantage of the charger/inverter system is a $32 \mathrm{~ms}$ switch over time. Some equipment may be sensitive to the switch over transient. Initially, a small 230 VAC/50 Hz UPS was used to avoid a problem with the NT workstation. This was later removed because of low AC voltages from the grid power and the charger/inverter system. The UPS was later replaced with a line conditioner.

To facilitate maintenance of the charger/ inverter system, a Trace TM500 monitoring meter (Figure 18c) was installed as part of the system. The TM500 monitored battery voltage, charge/ discharge current, and total current used. While in inverter mode the NT workstation, GPS receiver, and radio modems required about $10 \mathrm{amps}$ at about 12.5 volts to produce sufficient power at $230 \mathrm{VAC} / 50 \mathrm{HZ}$. At a $50 \%$ rating, it is estimated that the $2125 \mathrm{AMP} / \mathrm{Hr}$ batteries used for the charger/inverter system would keep the base station operating for about 12 hours (Figure 18d).

\section{Ethernet Hub}

One 10BaseT hub was provided with the NT workstation. The Linksys hub had 1 thinnet connector and 8 RJ45 receptacles. 110 VAC power is required for DC adapter provided by the manufacturer.

\section{Remote GPS Stations}

\section{SDA}

Items installed at SDA included the DGR115W Freewave radio modem (Figure 17b), Maxrad antenna, and antenna cable (Figure 20). The original Z-12R GPS receiver was used along with the existing solar panels, batteries, and power controller. The telemetry antenna was installed on a mast used for tiltmeter telemetry located about 20 meters from the GPS receiver and radio modem. The radio modem was connected to port A on the receiver via a DB9 RS232 connector that was wired to the waterproof connector on the radio modem. Polyphaser lightning surge suppressors were used on both the GPS receiver and radio modem.

Note: All Freewave radio modem antenna cables have male type $\mathrm{N}$ connectors. The older telemetry system used antenna cables with male type $\mathrm{N}$ connectors at the antenna end and male $\mathrm{BNC}$ connectors at the radio end.

\section{VIS}

This installation is similar to SDA except for the following: an existing antenna cable on the solar panel tower with male type $\mathrm{N}$ connectors was used and 4 new $100 \mathrm{amp} /$ hour deep cycle batteries were installed. VIS equipment was housed in a concrete bunker built specifically to house seismic, tilt, and GPS monitoring equipment. All equipment shares a common power system.

\section{SPT}

This installation was similar to VIS except for the following: an existing GPS telemetry cable was used with a BNC to type $N$ adapter (Figure 19) and an existing antenna was used. The SPT housing is identical to VIS. 


\section{GBSS Configuration}

GBSS processes for each GPS station have *.ini ascii files that contain startup values and parameters. When GBSS is first started the program is configured for a specific station. For example the *.ini file for the RVO base station is RVO_.ini. The first menu item is for communication parameters. A serial port is specified along with baud rate, data bits, stop bits, and parity. It is very important that the baud rate corresponds to $19.2 \mathrm{k}$ or to the baud rate selected for the radio modem. Radio modem baud rates have to correspond to baud rates set for the GPS receiver serial port used for communication.

Other GBSS configuration requirements are contained in the Magellan/Ashtech manual.

\section{REAL-TIME GPS MONITORING SYSTEM HARDWARE COMPONENTS}

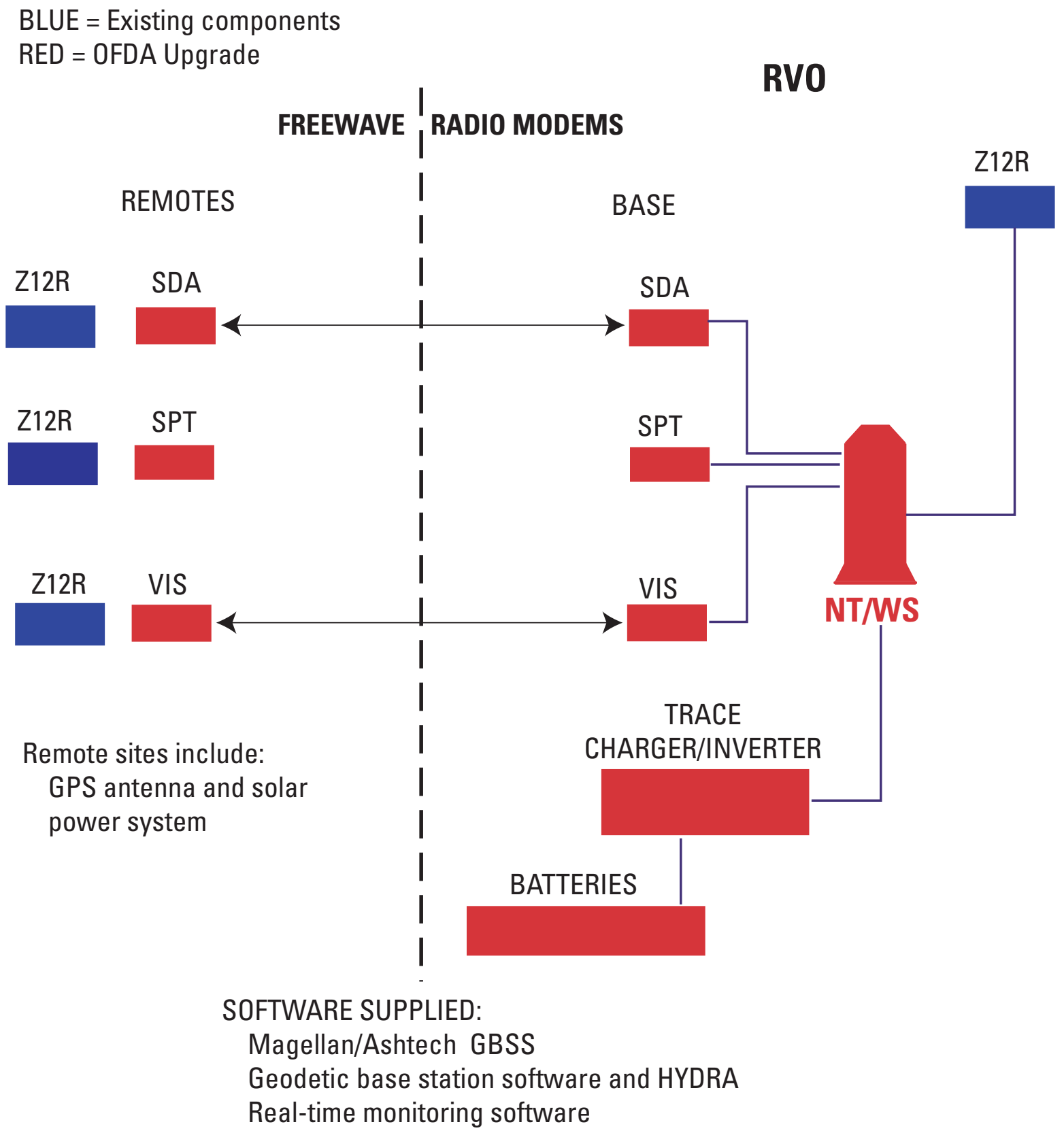

Figure 20. Schematic of components at each remote GPS station. 


\section{\# This file contains configuration information for GBSS.EXE}

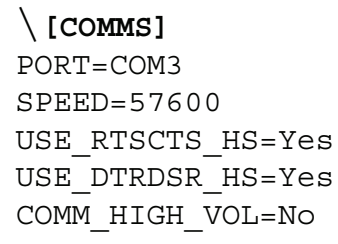

\section{[RECEIVER]}

TYPE $=Z-X I I 3$

CHAN VER $=1 D 04$

NAV $\bar{V} E R=1 L 00$

ALLOW_COMMANDS=Yes

CONNECT UPLOAD $=$ NO

CONNECT ULFILE=D: \source \ash gbss \upload.

tst

CNCTUPLD_PST_INIT $=$ NO

REC INT $=\overline{1} 0.0 \overline{0}$

EL_M MASK $=10$

UPLD_RECINT_ELMSK=Yes

UPLD_SITE_DATA=Yes

DISABLERCVRMEMLOG=Yes

\section{[SITE]}

$\mathrm{NAME}=\mathrm{RVO}$

ANT HEIGHT $=0.0000$

REF_POS $=-5625350.0110,2970460.1170$, -

463019.1460

[FILES]

PRIM_OUTPUT_PATH=E: $\backslash$ PRIMARY

SCND_OUTPUT_PATH=E: $\backslash$ Secondary

OUTPUT_BES_FILES=PRIMARY

OUT_L1BES_FILES=NO

OUTPUT_RNX_FILES=SECONDARY

OUT_LIRNX_FILES $=$ NO

OUTPUT_ION_FILES=NO

TRAP COMMS=NO

PRIM_COMPRES PATH=E: \PRIMARY

SCND_COMPRES_PATH=E: $\backslash$ PRIMARY

CMP BES FILES $=$ NO

CMP_L1BES_FILES $=$ NO

CMP_RNX_FILES=NO

CMP_LIRNX_FILES=NO

CMP ION FILES=NO

CMP_TRAP_FILE $=$ NO

FILTER_SECONDS $=30.000000$

FILE_DÜRATION $=24.000000$

FILE_REOPEN_RATE $=60$

FILE DELETION AGE $=-1.0$

USE_ASH_SUBDIRS $=$ Yes

\section{[OPTIONS]}

SNAV_CHKSUMS $=$ Yes

DIAG_LOG_FILE=PRIMARY

LOG_V VERBOSE_DIAGS $=$ NO

DISP_VERBOSE_DIAG $=$ Yes

PLAY WARNING_SND $=$ NO

WARNING_SOUND_FIL $=\mathrm{C}: \backslash$ Program Files $\backslash$ Ashtech $\backslash$

GBSS \Warning $\backslash$ BFWarn . wav

PLAY_ALERT_SOUND=NO

ALERT_SOUND_FILE=C: $\backslash$ Program Files $\backslash$ Ashtech $\backslash$
GBSS \Warning $\backslash j$ fdanger wav

SHOW_GBSS_BMP=Yes

\section{[WINDOWS ]}

MAINWIN $=0,0,127,1118,816$

GEOPOSWIN $=1,7,313,493,316$

ECEFWIN $=0,2,7,298,195$

CHANSUMWIN $=1,600,-4,493,182$

DIAGWIN $=1,493,318,584,314$

LOGSUMWIN $=1,-6,0,601,318$

TIMEWIN $=0,492,181,479,115$

POSTSESSWIN $=0,-1,1,608,207$

[TIME]

LOCAL2 GPSSECS $=-35971$

RCVTIMEFIXLCLTIME=Yes

LOCAL_TIME_ZONE $=10$

\section{[NMEA]}

CAPTURE_NMEA_FILE $=$ NO

CAPTURE_NMEA_GLL=Yes

CAPTURE_NMEA_APA=Yes

CAPTURE_NMEA_DAL=Yes

CAPTURE_NMEA_GRS=Yes

CAPTURE_NMEA SAT $=$ Yes

CAPTURE_NMEA GXP=Yes

CAPTURE_NMEA_ALM=Yes

CAPTURE_NMEA_GSA $=$ Yes

CAPTURE NMEA UTM=Yes

CAPTURE_NMEA_XDR=Yes

CAPTURE_NMEA_GGA=Yes

CAPTURE NMEA MSG $=$ Yes

CAPTURE_NMEA_GSV=Yes

CAPTURE_NMEA_VTS=Yes

CAPTURE_NMEA_VTG=Yes

CAPTURE NMEA XTE=Yes

CAPTURE NMEA TTT $=$ Yes

CAPTURE_NMEA_GSN=Yes

CAPTURE_NMEA_BWC=Yes

CAPTURE NMEA RRE=Yes

CAPTURE_NMEA_POS=Yes

\section{[ INTERRPTNS]}

WASLOGGING $=$ NO

LASTLOGTIME $=1048,102460$

TOTINTERRUPTIONS $=1$

LASTINTRUPTTIME $=1046,518817$

\section{[RINEXDAT]}

SITE_NUMBER=Station Number 1

CREATE AGENCY=RVO

OBSERVER=STEVE SAUNDERS

OBSERVER_AGENCY=RABAUL VOLCANO OBSERVATORY

COMMENT1 $1=$

COMMENT2 =

COMMENT $3=$

RCVR_SERNUM=RSO0144

ANT_TYPE=DORNE MARGOLIN ASH

ANT_SERNUM $=12752$

WRITE_EPINT=YeS

MS_OB $\bar{S}$ _HANDLING $=$ Yes

SMOOTH $\mathrm{CODE}=$ Yes

WRITE_SITE_CHNGS=Yes 
[POSTSESCMD]

NUM_POST_SES_CMD $=0$

[REALTIMEIF]

REALTIME_IF $=1$, GBSSRVO1

[EXTMODULES]

EXT_MODULE_1=NULL , 0 , NULL , 0 , NULL $\%+$ NULL EXT_MODULE_2=NULL , 0 ,NULL , 0 , NULL $\%+\frac{\circ}{\circ}$ NUL EXT_MODULE_3 $=$ NULL , 0 ,NULL , 0 , NULL $\%+$ NULL EXT_MODULE $4=$ NULL , 0 , NULL , 0 , NULL $\%+\frac{\circ}{0}$ NUL EXT MODULE $5=$ NULL , 0 , NULL , 0 , NULL $\%+\frac{N U L L}{0}$ EXT_MODULE_6 $=$ NULL , 0 ,NULL , 0 , NULL $\%$ NULL EXT_MODULE $7=$ NULL , 0 , NULL , 0 , NULL $\%+\frac{N U L L}{\circ}$ EXT_MODULE_ $8=$ NULL , 0 , NULL , 0 , NULL $\%+\frac{\circ}{\circ}$ NUL EXT_MODULE_9=NULL , 0 ,NULL , 0 , NULL $\%$ NULL EXT_MODULE_10=NULL , 0 , NULL , 0 ,NULL $\%+\frac{\circ}{\circ}$ NUL

\section{3d_tracker Configuration}

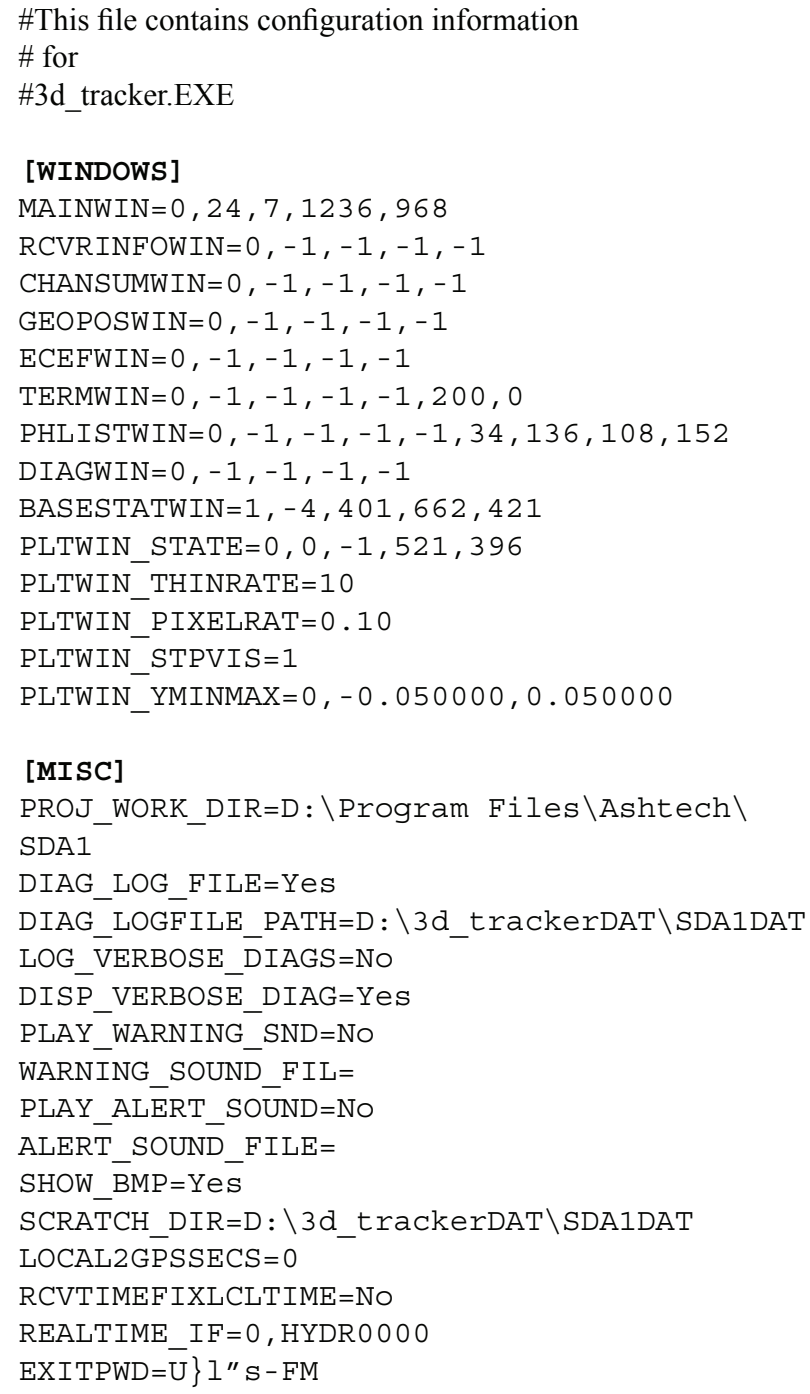

\section{SUMMARY}

The installation of real-time GPS capability was accomplished as scheduled and under budget. The initial technical assessment trip in late 1999 provided information required for the procurement and preparation of equipment in the U.S. The initial trip also provided an opportunity to meet with U.S. Embassy officials in Port Moresby where they were briefed on the progress of the project. In addition, arrangements were made for the customs clearance of equipment shipped to Papua New Guinea.

The project was made possible with GPS equipment provided by AusAID via AGSO and funding from AusAID for site preparation. The USGS installed telemetry, computer workstation, backup power and software required for implementation of real-time GPS monitoring. RVO provided technical and logistical support. Installed equipment and software performed as expected.

\section{ACKNOWLEDGMENTS}

Thanks to Ima Itikarai (RVO SIC) and the RVO staff for their support during both trips to Rabaul. John Bosco, RVO electronics engineer, played an important role in the success of the realtime GPS installation. The equipment shipped to Rabaul arrived intact and cleared customs with help from Robert Damien and James Gary at the American Embassy in Port Moresby.

\section{REFERENCES CITED}

Grewal, Mohinder S., and Andrews, Angus P., 1993, Kalman Filtering Theory and Practice, Prentice Hall, 381 p.

Remondi, Benjamin W., and Brown, R. Grover, 2000, Triple Differencing with Kalman Filtering: Making it Work, GPS Solutions, vol. 3, 3, 58-64.

Rutledge, David, Gnipp, Jack, and Kramer, John., 2001, Advances in Real-time GPS Deformation Monitoring for Landslides, Volcanoes, and Structures, Proceedings, $10^{\text {th }}$ FIG International Symposium on Deformation Measurements, p, 110-121. 
APPENDIXES 



\section{APPENDIX A. Short-Baseline Test Results of 3d_tracker}

Before shipping equipment to Rabaul in early January 2000, we conducted a short baseline $(\sim 3 \mathrm{~m})$ test of 3d_tracker at CVO. Magellan/ Ashtech Z-12's were used along with Dorne Margolin chokering antennas mounted on the roof of the CVO building. The NT workstation that was prepared for RVO was used to collect GPS data and for 3d tracker processing. Low Q Kalman filter (-10) and a high Q Kalman filter (-5) 3d_tracker processes were operated for several days to determine a definitive position for the "rover" antenna. The height of the antenna designated as remote was offset vertically by 3.8 $\mathrm{cm}$ with a SS standoff (Figure 21). We chose a vertical test because it is the most difficult parameter to measure with GPS.

A low Q Kalman filter process is very accurate but requires at least 24 hours for a reliable result. A high Q Kalman filter process responds very quickly to motion, however is susceptible to higher noise level. The noise level can be reduced in screen plots by time averaging of position changes. The low Q process does see a small change when the antenna is first moved (Figure 22). The high Q process recorded the change instantly (Figure 23) with an overshoot that is related to the actual height that the antenna was moved while placing it on a standoff. The low Q 3d_tracker process required 24 hours to detect the full $3.8 \mathrm{~cm}$ offset. Figure $24 \mathrm{a}$ and $24 \mathrm{~b}$ are 7 day plots of results from the same test.

The Kalman filter implementation is proprietary and is not discussed in this report. We treat 3d_tracker as a "black box" that produces a desired result. For more information on Kalman filters see Grewal and Andrews (1993) "Kalman Filtering Theory and Practice". For Kalman filtering applied to triple differencing GPS solutions see Remondi and Brown (1999).

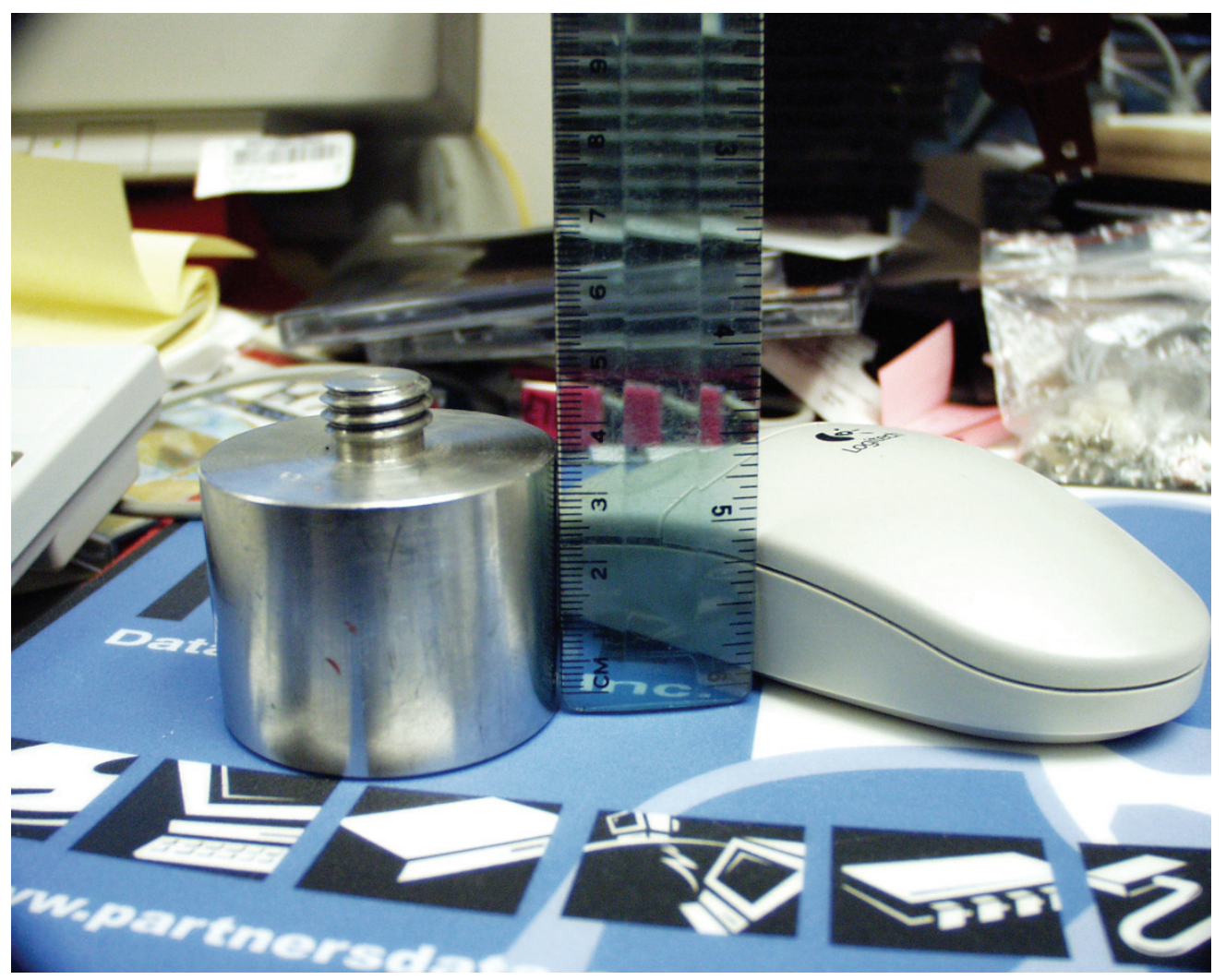

Figure 21. SS standoff used in the testing of vertical displacement of the rover GPS antenna. For our experiment the standoff was screwed to the case of the antenna and tribrach adapter. 


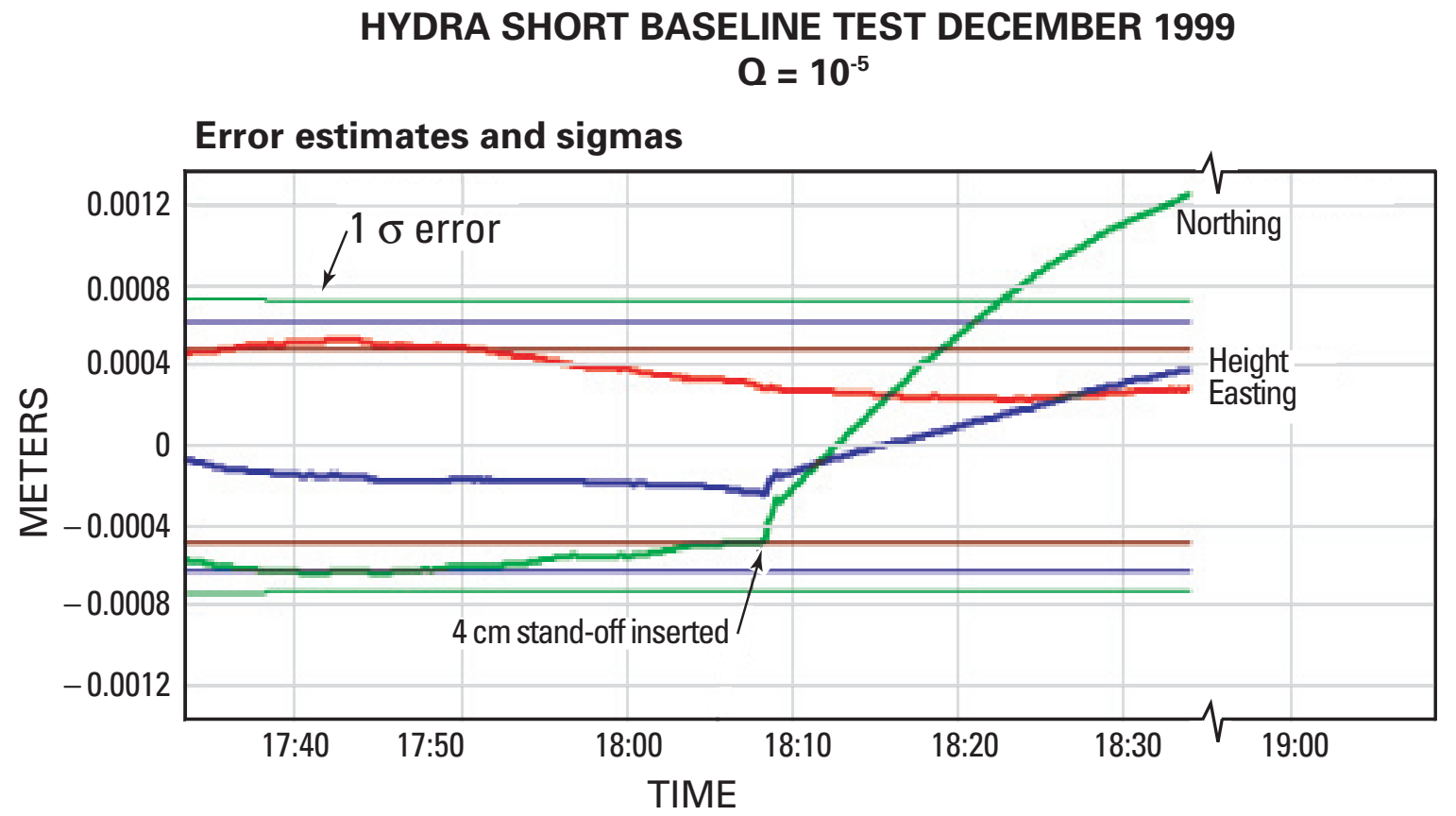

Figure 22. Low Q-screen capture of plot from 3d_tracker showing the onset of movement. Divisions are $0.0004 \mathrm{~mm}$ in the vertical and 10 minutes in the horizontal. The 1 sigma error bars are indicated. Northing showed an offset possibly owing to slight change in phase center when the antenna was moved.

HYDRA SHORT BASELINE TEST DECEMBER 1999

$Q=10^{-5}$

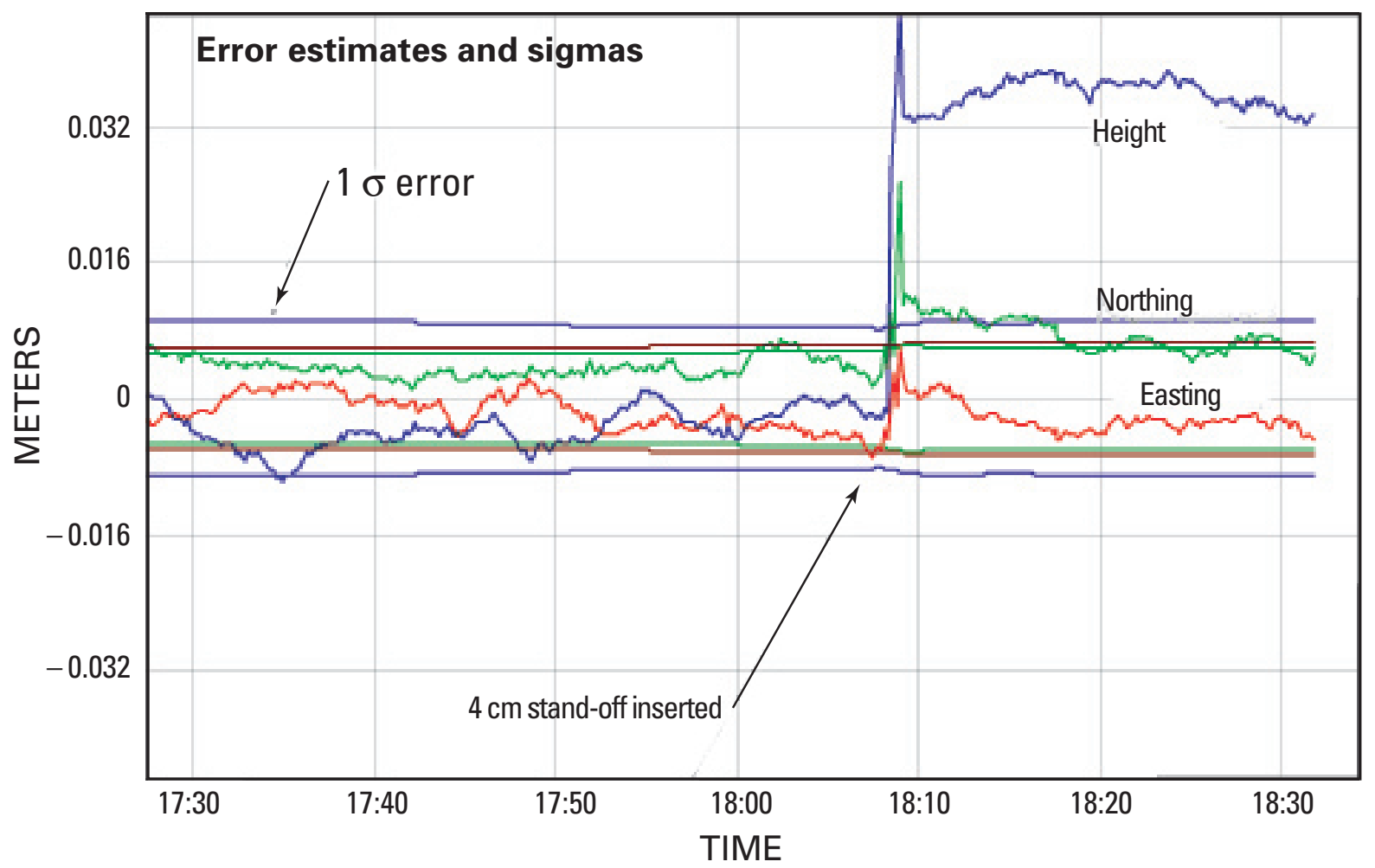

Figure 23. High Q-screen capture of plot from 3d_tracker instantly showing offset very close to the $3.8 \mathrm{~cm}$ total. Note northing is offset several millimeters. An antenna phase center error is suspected. 


\section{HYDRA SHORT BASELINE TEST 12/99}

\section{SECOND EPOCHS, 1 METER BASELINE}

$\boldsymbol{A}$

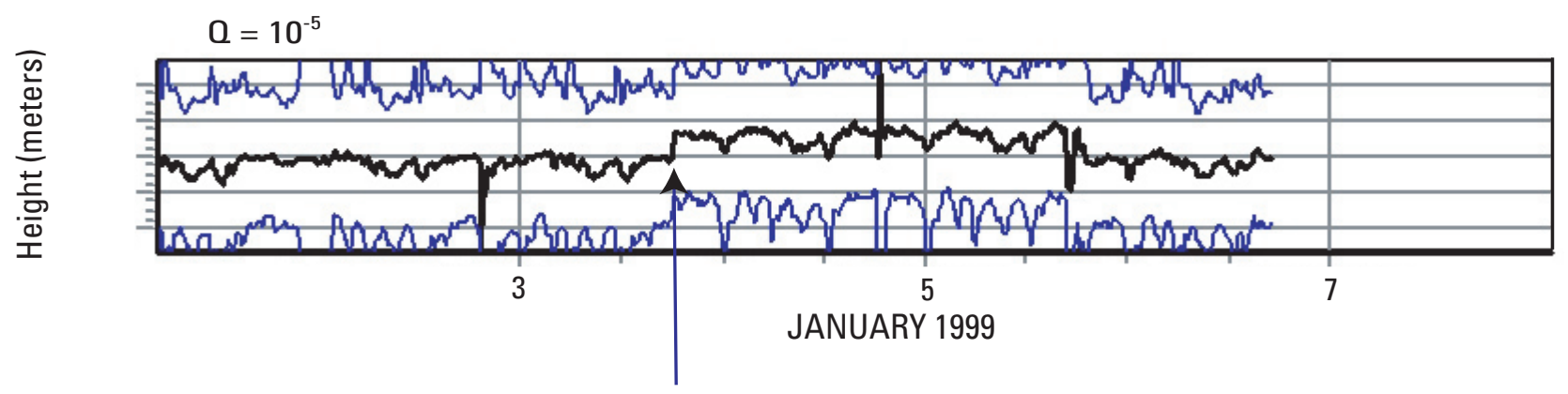

4 CM STAND-OFF INSTALLED

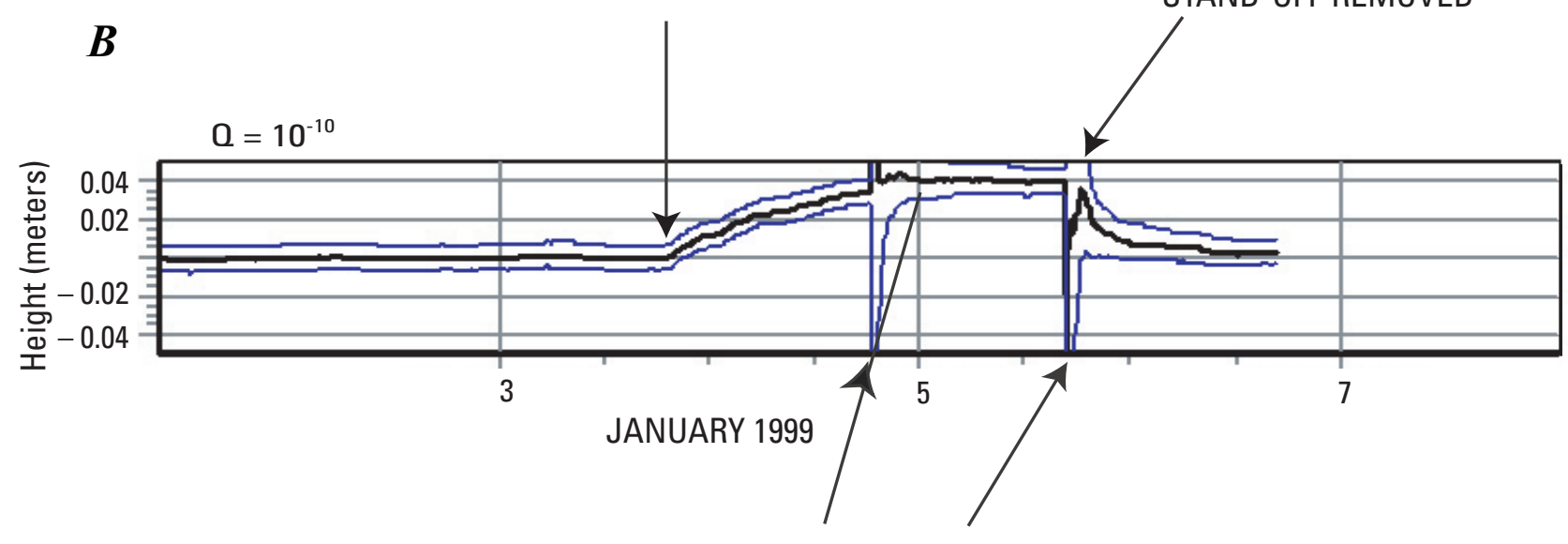

HYDRA INTENTIONALLY STOPPED

Figure 24. Seven-day plot of height for short baseline test. Plot $A$ is for the high $Q$ solutions and plot $B$ is for low $Q$ solutions. 
http://www.maxrad.com

Pasternack Enterprises

P.O. Box 16759

Irvine, CA 92623-6759 USA

Tel:(949) 261-1920 Fax:(949) 261-7451

http://www.pasternack.com

Polyphaser Corporation

2225 Park Place

Minden, NV 89423 USA

Tel:(775) 782-2511 Fax:(775) 4476

http://www.polyphaser.com

Trace Engineering Company, Inc.

$5916195^{\text {th }}$ Street N.E.

Arlington, WA 98223 USA

Tel:(360) 435-8826 Fax:(360) 435-2229

http://www.traceengineering.com

\section{APPENDIX B. Vendors}

Applied Power Corporation

1210 Homann Dr. S.E.

Lacey, WA 98503 USA

Tel:(360) 438-2110 Fax: (360) 438-2115

http://www.appliedpower.com

Magellan/Ashtech

471 El Camino Real

Santa Clara, CA 95050-4300

Tel:(408) 615-5100 Fax:(408) 615-5200

http://www.ashtech.com

Condor Earth Technologies, Inc.

21663 Brina Lane

P.O. Box 3905

Sonora, CA USA

Tel:( 209) 532-0361 Fax:(209) 532-0773

http://www.3d-gps.com

Dell

P.O. Box 224588

Dallas, Texas 75222-4588

Tel:(888) 349-2598

http://www.dell.com

Freewave Technologies, Inc.

1880 South Flatiron Court

Boulder, CO 80301 USA

Tel:(303) 444-3862 Fax:(303) 786-9948

http://www.freewave.com
Hutton Communications, Inc.

9825 Willows Rd

Redmond, WA 98052-1015 USA

Tel:(800) 426-2964

http://www.huttoncom.com

Maxrad, Inc.

4350 Chandler Drive

Hanover Park, IL 60103 USA

Tel:(800) 323-9122

http://www.maxrad.com

Pasternack Enterprises

P.O. Box 16759

Irvine, CA 92623-6759 USA

Tel:(949) 261-1920 Fax:(949) 261-7451

http://www.pasternack.com

Polyphaser Corporation

2225 Park Place

Minden, NV 89423 USA

Tel:(775) 782-2511 Fax:(775) 4476

http://www.polyphaser.com

Trace Engineering Company, Inc.

$5916195^{\text {th }}$ Street N.E.

Arlington, WA 98223 USA

Tel:(360) 435-8826 Fax:(360) 435-2229

http://www.traceengineering.com

\section{APPENDIX C. Manuals}

GBSS provided as a separate item to RVO. 3d_tracker provided as a separate item RVO.

Trace charger/inverter - provided as a separate item RVO 